\title{
Experimental study on dynamic compressive behaviour of recycled tyre polymer fibre
} reinforced concrete

Meng Chen ${ }^{\mathrm{a}}$, Wei Chen ${ }^{\mathrm{b}}$, Hui Zhong ${ }^{\mathrm{c}}$, Dong Chi ${ }^{\mathrm{a}}$, Yuhan Wang ${ }^{\mathrm{a}}$, Mingzhong Zhang, ${ }^{\mathrm{c}}$,

${ }^{a}$ School of Resource and Civil Engineering, Northeastern University, Shenyang 110819, China

b State Key Laboratory of Silicate Materials for Architectures, Wuhan University of Technology, Wuhan 430070, China ${ }^{\mathrm{c}}$ Department of Civil, Environmental and Geomatic Engineering, University College London, London WC1E 6BT, UK Abstract: The effect of recycled tyre polymer fibre (RTPF) on mechanical and durability performance of concrete has been increasingly studied in recent years, primarily because of the economic and sustainable feasibility of RTPF's application in construction industry. This paper presents an experimental study on workability, static compressive strength and dynamic compressive properties of concrete reinforced with RTPF with various fibre dosages (i.e. 1.2, 2.4, 4.8 and 9.6 $\mathrm{kg} / \mathrm{m}^{3}$ ) that have not been extensively investigated. Results indicate that the dynamic compressive properties including dynamic compressive strength, energy absorption capacity, ultimate strain and dynamic increase factor of all mixtures were highly sensitive to the strain rate. The optimal RTPF content was found to be $2.4 \mathrm{~kg} / \mathrm{m}^{3}$ (i.e. $0.2 \%$ fibre volume fraction $\left(\mathrm{V}_{\mathrm{f}}\right)$ ) considering fresh and hardened properties, as adding this content into concrete induced the most development in dynamic compressive strength (with the highest increase of 12.9\%), fracture energy (with the highest improvement of 54.4\%) and total energy absorption (with the largest enhancement of 26.4\%). It was found from scanning electron microscope (SEM) image analysis that RTPF exhibits bridging performance with no obvious fracture on its surface, and $0.1 \% \mathrm{~V}_{\mathrm{f}}$ of PPF could be replaced by $0.2 \%$ $\mathrm{V}_{\mathrm{f}}$ of RTPF for concrete.

Keywords: Fibre reinforced concrete; Recycled tyre fibre; Polypropylene fibre; Dynamic compressive behaviour; Failure mode

\section{Introduction}

It is generally acknowledged that the use of fibre reinforced concrete (FRC) can effectively mitigate the inherent brittleness nature and susceptible cracking problem of normal concrete by enhancing its tensile capacity, toughness, ductility and durability performance [1]. Over the past several decades, many different types of fibres were employed as the main constituent material of FRC and the most commonly used ones are steel [2-4], polypropylene [5-7] and glass fibres [8-10]. Additionally, polyvinyl alcohol and polyethylene fibres are mainly used for the development of high-performance FRC that exhibits superior mechanical strength, extraordinary ductility with strain-hardening behaviour and excellent durability under aggressive environments [11-17]. However, the increasing demand of the aforementioned constituent materials poses several challenges to the construction and material manufacture industries primarily due to the large energy consumption [18], in which the

\footnotetext{
* Corresponding author. Tel: +44 (0)20 7679 7299. E-mail address: mingzhong.zhang@ucl.ac.uk (M. Zhang)
} 
production of raw construction materials accounts for approximately $15 \%$ of the total building energy [19]. In addition to this, the induced environmental pollution is also not inevitable [18]. Recently, an increasing number of attempts have been made to recycle end-of-life materials or industrial byproducts as constituent or reinforcement materials for concrete in order to reduce the energy consumption and improve sustainability of concrete [20, 21]. Adopting end-of-life tyres and their constituents into cementitious materials is one of the most recent attempts as it can not only help promote the sustainable development (carbon dioxide emission can be reduced by avoiding the tyre burning [21]) but also significantly reduce the environmental impact of global landfill waste tyres (approximately 500 million tyres are disposed to landfills without any treatment yearly [21]).

End-of-life tyres can be utilized by reclamation, high pressure and high temperature sintering, energy recovery and pyrolysis [22]. Thermochemical processes including pyrolysis, gasification and liquefaction are generally undertaken for transferring the end-of-life tyres into recyclable products [23]. Through the shredding and electromagnetic processes, different constituents of waste tyres such as steel, rubber granules, textiles and polymer fibres can be separated [23, 24]. In the past decade, numerous studies [18, 24-32] have examined the effect of steel fibres recovered from waste tyres on the properties especially mechanical and durability performances of FRC focusing on the feasibility of partial or total replacement of manufactured steel fibres commonly used in FRC by recycled steel fibres. Centonze et al. [26] investigated the post-cracking behaviour of recycled steel-FRC and found that the incorporation of recycled steel fibres into concrete improved its energy absorption and residual strength after cracking, which is consistent with the findings by Caggiano et al. [29] and Zamanzadeh et al. [28] that recycled steel-FRC showed similar trend with industrial steel-FRC in terms of post-cracking behaviour under the same fibre content. Skarżyński and Suchorzewski [30] concluded that the concrete mixtures reinforced with higher recycled fibre cotents (i.e. two times higher) presented comparable properties to those reinforced with industrial steel fibres. The partial replacement of industrial steel fibres by recycled steel fibres in FRC resulted in a significant improvement in flexural performance and abrasion resistance of steel-FRC [18].

In addition, a number of studies demonstrated that partially replacing the aggregates by the rubber granules or particles in normal concrete can improve its abrasion resistance, resistance to freeze-thaw cycles and acid attack, and energy absorption capacity [21, 33-37] under certain conditions (e.g. appropriate replacement ratio and rubber size), while the effects were more pronounced when the rubber particles were pre-treated with sodium hydroxide solution because of the reduced porosity [38, 39]. Given these remarkable findings, the incorporation of raw materials recovered from waste tyres into concrete is regarded as a promising approach to develop sustainable construction material. However, it was reported that approximately 25,000 tonnes of polymer fibres are recovered annually from waste tyres in European Union (EU) only [40] and the large storage of these fibres poses a 
serious threat to the environment due to their high flammability and low density (i.e. potential contaminated source) [41]. Therefore, it is very urgent and crucial for researchers to find alternative usages for these recycled tyre polymer fibres (RTPF) and investigate the feasibility of incorporating these fibres into cementitious materials in order to develop FRC with higher sustainability.

Up to now, only a very limited number of studies [40-44] discussed the effects of RTPF on material properties of concrete, which found that the addition of RTPF into concrete can effectively mitigate its early-age deformation and enhance its resistance to plastic shrinkage cracking and fire. Moreover, it is suggested that RTPF has a great potential to replace manufactured polypropylene fibre (PPF) in FRC. PPF is considered to be the secondary reinforcement in normal concrete mostly used for construction applications such as blast resistant concrete, pavements and shotcrete tunnel linings and the demand of manufactured PPF would be consistently increasing [45]. Baričević et al. [40] experimentally investigated the influence of RTPF on mechanical properties and durability of concrete to evaluate the possibility of replacing commonly used PPF in FRC by RTPF. They found that the incorporation of RTPF into concrete can restrain the early-age deformation of concrete and improve its resistance to freeze-thaw cycles. The highest substitution contents of industrial PP fibres were $2 \mathrm{~kg} / \mathrm{m}^{3}$ and $10 \mathrm{~kg} / \mathrm{m}^{3}$ for cleaned and mixed RTPF, respectively. By incorporating RTPF into wet-sprayed concrete, it was observed that RTPF can effectively reduce the crack width and increase the tensile stress and resistance of concrete to cyclic freeze-thaw conditions, which can be attributed to the stress absorption capacity of residual rubber particles inside the RTPF used [41]. Serdar et al. [42] studied the shrinkage behaviour of RTPF reinforced concrete with different fibre content (i.e., 5, 10 and $15 \mathrm{~kg} / \mathrm{m}^{3}$ ). They noted that the autogenous shrinkage of concrete was significantly decreased because of the presence of RTPF and the use of higher RTPF dosage did not weaken the workability of normal concrete. Huang et al. [43] reported that concrete specimens reinforced by $2 \mathrm{~kg} / \mathrm{m}^{3}$ of RTPF did not spall under fire exposure demonstrating a significant improvement in fire resistance for concrete reinforced with RTPF. Onuaguluchi and Banthia [44] explored the durability performance of cement mortar reinforced with polyester-based RTPF and found that the incorporation of $0.4 \%$ fibre volume fraction $\left(\mathrm{V}_{\mathrm{f}}\right)$ of RTPF improved the plastic shrinkage cracking resistance of cement mortar. These previous studies have focused on static mechanical properties and durability of concrete reinforced with RTPF, while its dynamic mechanical properties have not been extensively studied. It is worth noting that FRC may suffer from serious dynamic impact near airport, marine, coastal and earthquake regions. The paucity of information on dynamic behaviour of concrete reinforced with RTPF would hinder its widespread application. Thus, it is of great practical significance and intrinsic scientific interest to explore the feasibility of replacing manufactured PPF with RTPF in concrete and the dynamic compressive behaviour of concrete reinforced with RTPF. 
This paper, for the first time, provides a comprehensive understanding of static and dynamic compressive behaviour of concrete reinforced with RTPF with various dosages (i.e., 1.2, 2.4, 4.8 and $9.6 \mathrm{~kg} / \mathrm{m}^{3}$ ) through a series of tests including split Hopkinson pressure bar (SHPB) test. A concrete mixture reinforced with $0.9 \mathrm{~kg} / \mathrm{m}^{3}$ (equivalent to $0.1 \% \mathrm{~V}_{\mathrm{f}}$ ) of PPF was prepared and used as a reference for comparison to investigate the feasibility of total replacement of manufactured PPF in FRC by RTPF. Firstly, static tests were conducted to measure workability and static compressive strength of specimens. Subsequently, dynamic tests using SHPB at six high impact velocities were undertaken to estimate the effects of strain rate and fibre dosage on dynamic compressive properties, including stress-strain curve, dynamic compressive strength and energy absorption capacity, failure pattern as well as dynamic increase factor (DIF) that was introduced to further understand the enhancement of dynamic compressive strength after incorporating fibres. Finally, a comparison between RTPF and PPF reinforced mixtures in terms of mechanical properties and scanning electron microscopy (SEM) images was presented.

\section{Experimental program}

\subsection{Materials}

The main binder material used in this work was Portland cement (P.I. 42.5) with a specific gravity of 3.09. The oxide composition of cement is listed in Table 1. Natural river sand with a nominal maximum size of $4.75 \mathrm{~mm}$ was used as the fine aggregate, the specific gravity of which is 2.56. Crushed granites with two different maximum particle sizes (i.e. 5 and $20 \mathrm{~mm}$ ) were mixed and used as the coarse aggregates. To improve the flowability of fresh mixtures, polycarboxylate-based superplasticisers (SPs) were added during the mixing process for all specimens, where the content was fixed as $1.0 \%$ by the mass of total binder for all mixtures.

Fig. 1 shows the chopped PPF and RTPF used in this study. RTPF recycled from truck tyres was supplied by a tyre recycling company in Shanghai, China (Jinghan rubber and plastic products Co. Ltd), which consists of 52\% polyethylene terephthalate (PET), 39\% polyamide 66 (PA 66) and 9\% polybutylene terephthalate (PBT) with a certain quantity of rubber particles attached. Laboratory sieves with different openings were applied to estimate the composition of RTPF, which contains cleaned RTPFs 56.8 wt.\% (Fig. 1c) and rubber particles 43.2 wt.\% (Fig. 1d). The geometrical characteristic of each obtained RTPF may vary depending on the type of waste tyres used during the recycling process [42]. The dimension of RTPF used in this study was determined by microscopic examination. The physical and mechanical properties of PPF and RTPF are presented in Table 2.

\subsection{Mixture proportions}

In this study, plain concrete specimens reinforced with two different types of fibres (i.e. PPF and RTPF) were prepared and tested. The mixture proportions are shown in Table 3, where all mixtures had the same water-to-binder (w/b) ratio of 0.28 . In Table 3, the labels 'F', 'PPF' and 'RTPF' stand 
for fibre, polypropylene fibre and recycled tyre polymer fibre, while the numbers ' 0 ', '09', '12', '24', '48' and '96' represent the specified fibre content of each corresponding fibre (e.g., '0' and '09' correspond to 0.0 and $0.9 \mathrm{~kg} / \mathrm{m}^{3}$, respectively). Baričević et al. [40] concluded that the addition of RTPF up to $5 \mathrm{~kg} / \mathrm{m}^{3}$ did not weaken the static mechanical properties of FRC, whereas the incorporation of RTPF over $10 \mathrm{~kg} / \mathrm{m}^{3}$ significantly reduced the mechanical properties suggesting that the upper limit of RTPF content for normal concrete is $10 \mathrm{~kg} / \mathrm{m}^{3}$. Thus, four different RTPF contents ranging from $1.2 \mathrm{~kg} / \mathrm{m}^{3}$ (i.e. $0.1 \% \mathrm{~V}_{\mathrm{f}}$ ) to $9.6 \mathrm{~kg} / \mathrm{m}^{3}$ (i.e. $0.8 \% \mathrm{~V}_{\mathrm{f}}$ ) were selected here to explore the optimal content and upper limit of RTPF in terms of dynamic compressive properties. F0 is referred to as the reference mixture (without fibre reinforcement). Previous studies [40, 46] concluded that 0.9 $\mathrm{kg} / \mathrm{m}^{3}$ (equivalent to $0.1 \% \mathrm{~V}_{\mathrm{f}}$ ) of PPF content was found to be optimal in obtaining the desirable mechanical properties of concrete and also efficient in restraining the early-age cracking. The addition of PPF into normal concrete with different fibre contents improved its impact resistance [5, 6, 47], whereas the effect of the aforementioned PPF content (i.e. $0.9 \mathrm{~kg} / \mathrm{m}^{3}$ ) on dynamic compressive properties of concrete has not been extensively investigated. Past research [40-42] reported that RTPF reinforced concrete exhibited better early-age cracking-control performance than that of PPF reinforced concrete, but the systematic comparison in terms of dynamic compressive behaviour has not been studied. Thus, concrete mixture reinforced with $0.9 \mathrm{~kg} / \mathrm{m}^{3}$ of PPF was prepared and used as a reference mixture, the fresh and hardened properties especially dynamic compressive properties of which were compared with those reinforced with RTPF to estimate whether PPF can be replaced by RTPF with same or higher fibre volume fraction.

\subsection{Mixing procedure and sample preparation}

The mixing procedure of all concrete mixtures investigated in this study consists of three stages. Cement, fine and coarse aggregates were first dry mixed for 2 mins. After this, water and SPs were gradually added into the dry mix. Lastly, PPFs or RTPFs were carefully added into the mixture ensuring uniform dispersion of the fibres. Afterwards, fresh mixtures were immediately cast into different sizes of moulds (cube with size of $150 \mathrm{~mm}$ for static compressive strength test and cylinder with size of $100 \mathrm{~mm} \times 50 \mathrm{~mm}$ for SHPB test), which were placed on a vibration table. In order to ensure the reliability of the result for each test, three specimens of each mixture were prepared for every testing age. After $24 \mathrm{~h}$ of casting, all mixtures were de-moulded and then stored in a standard curing room $\left(20 \pm 2{ }^{\circ} \mathrm{C}\right.$ and $\left.95 \% \mathrm{RH}\right)$ until the day of testing. Table 4 shows the experimental program including the number of performed tests per test set-up (test type), per testing age and per strain rate type for each mixture. 


\subsection{Testing methods}

\subsubsection{Workability test}

Slump test was conducted to determine the workability of each concrete mixture according to GB/T50080-2016 [48]. Herein, freshly mixed concrete specimens were cast into a specified cone mould and jolted for 25 times. Afterwards, the vertical displacement difference between the top of the mould and the top surface of the concrete specimens was measured.

\subsubsection{Static compressive strength test}

The static compressive strength was measured by using a universal testing machine in accordance with GB/T50081-2002 [49] at $7 \mathrm{~d}$ and $28 \mathrm{~d}$ for each mixture.

\subsubsection{Split Hopkinson pressure bar test}

SHPB technique is a commonly used method for measuring the dynamic properties of concrete under high strain rates from $10^{0}$ to $10^{4} \mathrm{~s}^{-1}[5,50]$. The dynamic compressive behaviour of all concrete mixtures was examined by a $100 \mathrm{~mm}$ SHPB apparatus at $28 \mathrm{~d}$ at six impact velocities (i.e., $\approx 5.4,7.6$, 8.6, 9.6, 10.4 and $10.8 \mathrm{~m} / \mathrm{s}$ ). Fig. 2 shows a schematic illustration of SHPB device used in this study, which was made of a superior alloy steel material and has a diameter of $100 \mathrm{~mm}$. The lengths of bullet, incident, transmission and absorbing bars are 600, 5000, 3500 and $1200 \mathrm{~mm}$, respectively.

Before the SHPB test, the specimen was sandwiched between the incident and transmission bars. Once the start button on the computer system was clicked, the bullet was propelled by the compressed nitrogen. Then, the incident bar shown in Fig. 2a was impacted by the $100 \mathrm{~mm}$ bullet with a measurable velocity detected by the speed detection devices (see Fig. 2a) before the impact. An incident pulse $\left(\varepsilon_{i}(t)\right)$ known as incident wave was subsequently generated. When the incident wave reached the interface between the incident bar and the specimen, a part of the incident wave was reflected from the specimen due to the impedance difference between the incident bar and the tested specimen [51] as a reflected pulse $\left(\varepsilon_{r}(t)\right)$, while the remaining was transmitted through the specimen into the transmission bar, known as transmission pulse $\left(\varepsilon_{t}(t)\right)$.

As shown in Fig. 3a, two strain gauges were attached on the incident and transmission bars to record the strain pulses, where the strain gauges were adhered symmetrically on the upper bar surface across a bar diameter (see Fig. 3b). In addition, the distance between the strain gauge and the specimen on the incident bar is equal to that on the transmission bar, i.e. $2500 \mathrm{~mm}$. During the SHPB test, the strain pulses $\left(\varepsilon_{i}, \varepsilon_{r}\right.$ and $\left.\varepsilon_{t}\right)$ shown in Fig. 3a were recorded through two strain gauges along with digital oscilloscope, where the strain gauges signals are presented in the form of strain against time. Fig. 4a shows the typical signals recorded from the strain gauges and digital oscilloscope without the application of pulse shaping technique. During the testing process, the pulse shaping technique was applied to improve the accuracy of SHPB results, where the main aim was to ensure the stress equilibrium within the specimen can be achieved via prolonging the rising time of the 
incident pulse. In addition, the shaping technique can be used to eliminate the influence of dispersion and inertia through smoothing the incident wave [5]. Hence, the pulse shaper with the size of $50 \mathrm{~mm}$ in diameter and $2 \mathrm{~mm}$ in height (see Fig. 5) was used. As shown in Fig. 4a, the typical waveforms without applying a pulse shaper were affected by the inertia effect of SHPB test (more triangular waveforms were observed), whereas the waveforms presented in Fig. $4 \mathrm{~b}$ were smoother with a long ramp after using a pulse shaper. As a result, the strain signals shown in Fig. 4 b were used to determine the changes in stress $\left(\sigma_{s}(t)\right)$, strain $\left(\varepsilon_{s}(t)\right)$ and strain rate $\left(\dot{\varepsilon}_{s}(t)\right)$ using Eq. (1) based on the theory of elastic stress wave propagation [52-54] with two main assumptions: (1) one-dimensional elasticity wave of the bars; and (2) axially uniform stress (or strain) in the tested samples.

$$
\left\{\begin{array}{l}
\sigma_{s}(t)=\frac{E A_{0}}{2 A_{s}}\left[\varepsilon_{i}(t)+\varepsilon_{r}(t)+\varepsilon_{t}(t)\right] \\
\varepsilon_{s}(t)=\frac{C_{0}}{l_{s}} \int_{0}^{t}\left[\varepsilon_{i}(t)-\varepsilon_{r}(t)-\varepsilon_{t}(t)\right] d t \\
\dot{\varepsilon}_{s}(t)=\frac{C_{0}}{l_{s}}\left[\varepsilon_{i}(t)-\varepsilon_{r}(t)-\varepsilon_{t}(t)\right]
\end{array}\right.
$$

where $E$ represents the elastic modulus of the bars (MPa), $A_{0}$ is the cross-sectional area of the bars $\left(\mathrm{mm}^{2}\right), A_{\mathrm{s}}$ is the cross-sectional area of the tested sample $\left(\mathrm{mm}^{2}\right), C_{0}$ is the longitudinal wave velocity of the bars $(\mathrm{m} / \mathrm{s})$ and $l_{\mathrm{s}}$ denotes the original thickness of the tested sample $(\mathrm{mm})$.

Fig. 6 shows an example of how the final curves of each mixture presented in Fig. 9 was derived. Basically, the final curve was obtained by averaging the curves of three specimens, and then the average strain rate was correspondingly determined. Given the fact that concrete is brittle and inhomogeneous in nature with very low failure strain under high-velocity impact [54], even for the same mixture the strain rate of each specimen would be different under the same velocity (see Fig. 6). Nevertheless, the pulse shaping technique mentioned previously can be used to ensure the stress equilibrium and nearly constant strain rate for each tested specimen over the entire testing period [5456], which improves the reliability of SHPB results.

\subsubsection{Scanning electron microscopy test}

To explore the morphology of PPF and RTPF inside the concrete matrix, SEM test (Ultra-plus SEM, Germany) was performed on the fracture pieces after the SHPB test. Before the test, all selected pieces were coated with a gold film. Regarding the image acquisition parameters, the working distance for the SEM test was set in the range of 10 to $17 \mathrm{~mm}$, while the acceleration voltage was $15 \mathrm{kV}$. The magnification was in the wide range of $100 \times$ and $800 \times$. 


\section{Results and discussion}

\subsection{Workability}

Workability is a crucial fresh property of concrete, as insufficient workability will negatively influence its mechanical properties. Hence, it is essential to investigate the effect of RTPF used in this study on workability of concrete with the same w/b ratio and fixed content of SPs.

Fig. 7 presents the slump value of all mixtures. It can be clearly observed that, independent of fibre dosage, the slump value of concrete was decreased with the presence of either PPF or RTPF. With the further increase of RTPF content, the reduction in workability was found to be more pronounced. In comparison with the slump value of the reference mixture (F0), the slump value of RTPF12, RTPF24, RTPF48 and RTPF96 was declined by $8.1 \%, 18.9 \%, 35.1 \%$ and $62.2 \%$, respectively, which indicates that the RTPF content equal to or above $4.8 \mathrm{~kg} / \mathrm{m}^{3}$ (i.e. $0.4 \% \mathrm{~V}_{\mathrm{f}}$ ) significantly influenced the consistency of fresh concrete mixtures. This result is consistent with previous studies $[40,57]$ mentioning that the workability of fresh concrete reinforced with RTPF was reduced with the increase of RTPF content. This can be explained as follows: (1) the incorporation of RTPF increases the shear resistance to the flow of fresh mixtures resulting in the segregation of raw materials; (2) the w/b ratio in this study was relatively low (i.e. 0.28 ), and thus a certain quantity of water may be absorbed by the RTPF and rubber granules during the mixing process, leading to lower flowability and higher viscosity for fresh mixtures. Consequently, the workability of fresh concrete mixtures reinforced with RTPF is found to be lower than those without fibre. In addition, for the same fibre volume fraction $\left(0.1 \% \mathrm{~V}_{\mathrm{f}}\right)$, the slump value of RTPF12 was slightly higher (about 7.6\%) than that of PPF09 while RTPF24 (i.e. $0.2 \% \mathrm{~V}_{\mathrm{f}}$ ) showed a comparable slump value with that of PPF09 (no more than 5.0\% difference) implying that, the lower workability issue of PPF reinforced concrete could be potentially mitigated by wholly replacing the PPF in concrete by RTPF. As mentioned above, the reduction in flow would influence the compactness of concrete mixture and accordingly affect its hardened properties. Therefore, the content of RTPF over $4.8 \mathrm{~kg} / \mathrm{m}^{3}$ (i.e. $0.4 \%$ $\mathrm{V}_{\mathrm{f}}$ ) should be avoided in order to ensure enough consistency for concrete reinforced with RTPF.

\subsection{Static compressive strength}

The effects of PPF and RTPF on compressive strength of concrete were examined at the ages of $7 \mathrm{~d}$ and $28 \mathrm{~d}$, the results of which are presented in Fig. 8. It can be found that the addition of RTPF up to content of $4.8 \mathrm{~kg} / \mathrm{m}^{3}$ (i.e. $0.4 \% \mathrm{~V}_{\mathrm{f}}$ ) did not present a significant effect on the compressive strength at $7 \mathrm{~d}$ and $28 \mathrm{~d}$ (no more than $8.5 \%$ difference), whereas with the incorporation of RTPF content of 9.6 $\mathrm{kg} / \mathrm{m}^{3}$ (i.e. $0.8 \% \mathrm{~V}_{\mathrm{f}}$ ), the $7-\mathrm{d}$ and 28 - $\mathrm{d}$ compressive strength was decreased by $23.0 \%$ and $17.7 \%$ respectively, indicating that the early-age compressive strength was influenced more significantly. This is in good agreement with the findings by Baričević et al. [40] that the compressive strength of concrete was declined up to $25.0 \%$ with the incorporation of mixed RTPF (i.e. $15 \mathrm{~kg} / \mathrm{m}^{3}$ ) in 
comparison with plain concrete, while the addition of lower RTPF dosage (up to $1.8 \mathrm{~kg} / \mathrm{m}^{3}$ ) slightly improved the compressive strength of plain wet-sprayed concrete. Thus, it can be concluded that there is no significant enhancement in compressive strength of concrete after adding RTPF, which can be partially attributed to the higher air contents of residual rubber particles inside the mixed RTPF (approximately $0.432 \mathrm{~kg}$ per $1 \mathrm{~kg}$ of RTPF) [40]. The rubber granule inside RTPF tends to attract more air content during the mixing process due to its nature of repelling water [58]. As a result, the overall porosity of concrete increases with the increase of entrained air content, leading to lower compressive strength and poorer durability performance. The compactness of RTPF reinforced mixtures decreased due to the reduced workability (mentioned in Section 3.1), causing negative influence on the mechanical property. Besides, the stiffness of cement matrix surrounding by small rubber particles is lower than that without rubber particles [21]. Thus, this softer cement matrix may result in a faster development of cracks during loading and consequently speeds up the failure of specimens.

As shown in Fig. 8, the 28-d compressive strength of PPF09 was reduced by 5.8\% as compared to F0, which was even lower than that of RTPF12, RTPF24 and RTPF48. The more pronounced negative influence on the compressive strength induced by PPF than RTPF indicates that RTPF is feasible to replace PPF in FRC if solely considering compressive strength. Thus, it can be concluded that the optimal limit of RTPF content is $4.8 \mathrm{~kg} / \mathrm{m}^{3}$ (i.e. $0.4 \% \mathrm{~V}_{\mathrm{f}}$ ) in terms of static compressive strength as excessive RTPF content reduces the compressive strength of concrete significantly.

\subsection{Dynamic compressive properties}

\subsubsection{Effect of strain rate}

Fig. 9 shows the effect of different strain rates varying from 37.8 to $123.5 \mathrm{~s}^{-1}$ on dynamic stress-strain curve of concrete mixtures at $28 \mathrm{~d}$. A conspicuous phenomenon can be observed that all mixtures had a common feature in terms of dynamic compressive behaviour, in which the dynamic compressive strength (i.e. maximum stress on the stress-strain curve) was enhanced with increasing strain rate. As strain rate changes, the dynamic compressive strength of F0, PPF09, RTPF12, RTPF24, RTPF48 and RTPF96 was increased by 4.8-90.6\%, 7.2-93.2\%, 7.3-112.4\%, 9.6-116.6\%, 6.4-91.8\% and 5.8-87.5\%, respectively. Previous studies $[4,5,50,59]$ also observed this strain rate dependent behaviour for FRC, which is known as strain rate effect. This may be ascribed to the lateral inertial effect on the surface of tested sample during the SHPB test or can be explained from the perspective of energy balance theory under high strain rate dynamic loading [51, 60-62]. When the strain rate is higher (i.e. higher impact velocity and shorter impact time), very large external energy created by the bullet impacts the specimen. Hence, in order to balance the external energy absorption, the internal strain energy of the specimen is significantly increased leading to cracks. As the energy required to create cracks is higher than the energy needed for the micro-cracks to propagate, the micro-cracks of the 
specimen mainly caused by the external impact load have no enough time to propagate prior to final failure due to the extremely short impact loading time, but more new cracks are generated. As a result, the dynamic compressive strength increases as the strain rate or impact velocity rises. This phenomenon is well consistent with the failure pattern of each investigated mixture (see Fig. 10). Unlike the concrete failed under normal static loading, with the increase of strain rate, the failure patterns of all mixtures showed similar features, which changed from splitting failure (see Fig. 10a, e, i, m, q and u) to pulverization failure (see Fig. 10d, h, 1, p, t and x). In addition, the damage level of each specimen increased with increasing strain rate, which shows a good agreement with previous studies $[4,50,63,64]$ reporting that bigger irregular broken elements were observed at a low strain rate, whereas specimens were broken into many tiny elements (failure of aggregates was also identified) at higher strain rates. The change of failure mode can also be ascribed to the extremely short impact time under the high impact velocity and therefore, the internal micro-cracks does not have enough time to propagate but more cracks are generated. Thus, the dynamic compressive stress enhanced significantly with the aim of providing energy for the generation of cracks at higher strain rates $[5,64]$. However, the increasing rate for dynamic compressive strength at a high strain rate was lower than that at a low strain rate, which can be attributed to the presence of free water inside the concrete [4].

Dynamic increase factor (DIF) that is defined as the ratio of dynamic compressive strength to static compressive strength has been widely used to describe the strain rate dependency of concrete materials $[4,51]$. It can be seen clearly from Table 5 that the DIFs of all mixtures were higher than 1 when the strain rate was higher than $58.6 \mathrm{~s}^{-1}$ suggesting that, the dynamic compressive strength was higher than static compressive strength beyond a certain impact velocity. Besides, the DIFs increased gradually with increasing strain rate. It was reported by previous studies that a linear relationship can be found between the DIF and the logarithm of strain rate, which is an essential parameter for ensuring an appropriate structural design [4]. Fig. 11 shows the fitted linear curves of DIF against logarithm of strain rate for all mixtures, where all tested mixtures presented a similar trend. The reliability of the curves can be evaluated by the corresponding correlation coefficients $\left(R^{2}\right)$ shown in Table 6 . The values of all $\mathrm{R}^{2}$ are higher than 0.9 indicating very high reliability and quality for all fitted functions (see Table 6).

The fracture energy presented in Table $\mathbf{5}$ is defined as the energy absorbed by the specimen up to the peak stress during the SHPB test, while the total energy reflects the energy absorption capacity in both pre-peak and post-peak regions. It can be observed obviously that both parameters enhanced with the increase of strain rate (ranging from $2.1 \%$ to $339.5 \%$ ) that is consistent with previous research $[4,5]$. The increasing energy absorption capacity can also be attributed to the generation of many cracks within the extremely limited loading time at the high strain rate, which agrees well with the 
failure modes presented in Fig. 10. The energy absorption capacity of the specimen is well correlated with the dynamic compressive stress and failure mode during dynamic compressive testing, indicating that as the strain rate increases, the energy absorption capacity and dynamic compressive strength stress improves accordingly along with more micro- or macro-cracks presented in the failure sample. Differently, for FRC, except for the energy absorbed due to the crack generation, additional amount of energy is required to pull out the fibres across the fracture zone.

The strain at peak stress and ultimate strain listed in Table $\mathbf{5}$ indirectly represent the deformation capacity of concrete materials [34], which were improved with increasing strain rate. The ultimate strain of each mixture was approximately $50.0 \%$ higher than its strain at peak stress. The ultimate strain of FRC in this study was higher than that of F0 especially at the low strain rate (i.e. the highest difference was approximately 120.5\%), while the strain difference reduced with increasing impact velocity (i.e. the difference dropped to around $24.8 \%$ at the strain rate of $120 \mathrm{~s}^{-1}$ ). This can be attributed to the bridging action of the fibres with the presence of cracks, which prolongs the strainsoftening region and subsequently improves the toughness of FRC. The strain of F0 at peak stress was reduced by about $2.2 \%$ when the strain rate increased from 111.7 to $123.5 \mathrm{~s}^{-1}$, which is known as strain rate hardening behaviour [5] and may be ascribed to the inhomogeneous nature of F0.

\subsubsection{Effect of RTPF content}

Fig. 12 shows the effect of RTPF content on dynamic compressive strength of concrete at various strain rates. The dynamic compressive strength of concrete at different strain rates (over $63 \mathrm{~s}^{-1}$ ) was increased with the increase of RTPF content up to $2.4 \mathrm{~kg} / \mathrm{m}^{3}$ (i.e. $0.2 \% \mathrm{~V}_{\mathrm{f}}$ ) followed by a decrease with the further incorporation of RTPF. With the addition of RTPF of $1.2 \mathrm{~kg} / \mathrm{m}^{3}$ and $2.4 \mathrm{~kg} / \mathrm{m}^{3}$, the dynamic compressive strength was increased the most at the strain rate of $75 \mathrm{~s}^{-1}$, i.e., $5.1 \%$ and $12.9 \%$, respectively. When the strain rate was higher than $63 \mathrm{~s}^{-1}$, the RTPF content that led to the highest enhancement in dynamic compressive strength was $2.4 \mathrm{~kg} / \mathrm{m}^{3}$, which suggests that the optimal RTPF content in this aspect is $2.4 \mathrm{~kg} / \mathrm{m}^{3}$. From the perspective of failure pattern, at relatively lower strain rates (i.e. 58.6-63.0 s ${ }^{-1}$ ), the concrete specimen without fibre incorporation (i.e. F0) presented more fracture pieces and its core-area's integrity was damaged severely (see Fig. 10a). However, the failure appearances of specimens reinforced with RTPF were more complete (see Fig. 10i, m, q and u), preserving the core-area's integrity (i.e. less macro-crack with smaller crack width). This implies that the addition of fibres can help restrain the crack growth and improve the resistance of specimens against dynamic loadings when the strain rate is low (below $63.0 \mathrm{~s}^{-1}$ in this study) [50, 65]. Within this range of strain rate, the dynamic compressive strength of RTPF reinforced mixtures increased approximately 2.7-7.1\% as compared to F0. Nevertheless, as the strain rate increased (see Fig. 10b, $\mathrm{j}, \mathrm{n}, \mathrm{r}, \mathrm{v}, \mathrm{c}, \mathrm{k}, \mathrm{o}, \mathrm{s}, \mathrm{w}, \mathrm{d}, \mathrm{l}, \mathrm{p}, \mathrm{t}$ and $\mathrm{x}$ ), F0 and RTPF reinforced mixtures presented similar failure patterns under specific range of impact velocity, indicating that the cracking control behaviour of the 
fibres decreased. This reduction in fibre efficiency is partially due to the increasing number of cracks with larger sizes within an extremely short impact time, and thus there is no sufficient time for fibres to exert their influences [4]. Besides, the bonding area between fibres and matrix reduced with the increasing strain rate due to the matrix rupture and low stiffness of fibres, and thereby weakening the fibre strengthening effect [65]. The dash grey line shown in Fig. 12 represents the development of dynamic compressive strength of RTPF24 with varying strain rate. It can be found that the dynamic compressive strength of RTPF24 increased by approximately $116.6 \%$ when the strain rate changed from 40 to $60 \mathrm{~s}^{-1}$, implying that RTPF was remarkably efficient in restraining the growth of crack. However, the considerable increase in dynamic compressive strength might be partially contributed by the strain rate effect [66]. With the further increase of the strain rate, the RTPF was found to be less effective in controlling the cracking mechanism of concrete as the increase percentages were decreased, ranging from $9.6 \%$ to $14.8 \%$, which can be attributed to the extremely short impact time and increase of bond failure between fibres and matrix, as explained previously. Furthermore, it can be observed that with the further addition of RTPF (higher than $2.4 \mathrm{~kg} / \mathrm{m}^{3}$ ), the dynamic compressive strength of concrete presented a descending trend, which can be mainly ascribed to the combined result of decreasing workability with the excess of RTPF and nonuniform distribution of RTPF inside the concrete matrix. As mentioned in Section 3.2, the mechanical properties of concrete mixture would be negatively affected by the reduced workability. In addition, more RTPFs inside the concrete mixture may increase its porosity affecting the mechanical and durability performances. Previous studies $[4,5,64]$ noted the importance of random distribution of fibres inside the matrix for FRC pointing out that a certain amount of fibre within the matrix plays an important role in forming a highquality internal structure. The mechanical properties including dynamic property of FRC would be affected by the quality of its internal structure with various influencing factors such as fibre orientation and fibre properties [4, 64]. Moreover, the infinitesimal amount of crumb rubber attached to the RTPF (i.e. $2.07 \mathrm{~kg} / \mathrm{m}^{3}$ and $4.15 \mathrm{~kg} / \mathrm{m}^{3}$ for RTPF48 and RTPF96) may slightly affect the positive influence on the dynamic compressive strength generated by the incorporation of clean RTPF. Liu et al. [34] reported that the presence of crumb rubber (around $11.64 \mathrm{~kg} / \mathrm{m}^{3}$ ) into concrete decreased its dynamic compressive strength by $17.0-23.0 \%$ at various strain rates ranging from 49.9 to $92.4 \mathrm{~s}^{-1}$ compared to that of plain concrete, suggesting that a certain amount of crumb rubber may weaken the dynamic property of concrete. This could be possibly due to the low specific gravity of rubber granules, which moves upward during the vibration process increasing the inhomogeneity of hardened mixtures. In this study, RTPF48 and RTPF96 presented better dynamic compressive strength than the plain mixture (i.e. F0), but the improvements (i.e. 2.5-8.7\% and 1.3-4.6\% respectively) were lower than that of RTPF24 (i.e. 6.3-12.9\%), implying that $2.4 \mathrm{~kg} / \mathrm{m}^{3}$ is the optimal fibre amount regarding this aspect. 
The influence of RTPF content on energy absorption capacity of concrete is demonstrated in Fig. 13, where the energy absorbed can be associated with the ductility of the material. Fig. 13a shows the development of fracture energy of FRC mixtures with varying RTPF content. The trend of fracture energy was similar to that of dynamic compressive strength, i.e., an increase up to the RTPF content of $2.4 \mathrm{~kg} / \mathrm{m}^{3}$ followed by a gradual decrease with further addition of RTPF at different strain rates, except the lowest one. As strain rate increased, the increase of fracture energy became more pronounced. For instance, the fracture energy of RTPF12 and RTPF24 was enhanced by $6.4 \%$ and $27.5 \%$ respectively at the strain rate of $75 \mathrm{~s}^{-1}$ compared to that of the reference mixture (F0), while the fracture energy of them was increased by $15.7 \%$ and $54.4 \%$ respectively at the strain rate of $95 \mathrm{~s}^{-}$ 1. Additionally, the specimens with the RTPF content of $2.4 \mathrm{~kg} / \mathrm{m}^{3}$ showed the highest fracture energy regardless of strain rate (except the strain rate of $40 \mathrm{~s}^{-1}$ ). It is worth pointing out that the energy absorbed by FRC in post-cracking zone was found to be higher than that up to the peak stress, ranging from $8.0 \%$ to $93.7 \%$, which is mainly due to the additional amount of energy required for FRC to pull out or rupture the fibres across the cracking zone. Thus, the energy absorbed in post-cracking zone was the dominant part of total energy absorption for FRC, which is in consistence with a previous study [34] showing that the addition of steel fibres bridged the fracture zone dissipating a large amount of energy. As seen in Fig. 10, the presence of RTPF helped preserve the core-area's integrity of the failure specimens when the strain rate was between 58.6 and $63.0 \mathrm{~s}^{-1}$, showing superior bridging action of the fibres that dissipates a large proportion of energy. As previously discussed, although the fibre efficiency decreased with increasing strain rate, the incorporation of fibres into concrete still improved its post-cracking performance as more large fracture elements can be observed for RTPF reinforced mixtures instead of many small fracture elements identified for F0. However, the differences in terms of failure modes at a higher strain rate were negligible. This is due to the increasing number and size of cracks as the strain rate rises and therefore, relatively shorter length of RTPF with lower stiffness was probably pulled out or ruptured during the bridging process but more energy was dissipated compared to that without fibre incorporation. In addition, less micro-cracks were presented inside the concrete specimens reinforced with RTPF. The rubber particles attached the RTPF may increase the frictional resistance during the pull-out process, which requires more energy to pull out the fibres. Overall, it suggests that the energy absorption mechanism for FRC under dynamic loading is the combination of the generation of many cracks under extremely short impact time and fibre pull-out behaviour during the fibre bridging process. A similar tendency can be seen from Fig. 13b that the RTPF content of $2.4 \mathrm{~kg} / \mathrm{m}^{3}$ was corresponding to the maximum total energy absorption capacity and thus it can be regarded as the optimal dosage regarding the energy absorption capacity. 
Fig. 14 shows the energy absorption capacity of RTPF24 at two different stages. The energy absorbed in the post-cracking zone of RTPF24 was consistently higher than its fracture energy at different strain rates, which supports the previous discussion that the energy absorbed by FRC is mostly generated in the post-cracking zone. It should be mentioned that the efficiency of RTPF in absorbing energy is associated with its bonding mechanism in concrete, and normally the better the bonding performance with the concrete matrix (higher interfacial bond strength), the higher the resistance to fibre pull-out. Accordingly, the energy absorption capacity and dynamic compressive strength will be higher. The energy absorption development of RTPF24 with increasing strain rate shown in Fig. 13a and b (i.e. grey lines) demonstrates that the RTPF lost its effectiveness in absorbing the energy when the strain rate is too high (i.e. decreased from $209.4 \%$ to $14.2 \%$ and $137.6 \%$ to $16.0 \%$, respectively), which supports previous discussions.

Fig. 15 shows the effect of RTPF content on DIF of concrete. The DIF at various strain rates was increased with the increase of RTPF content and then decreased slightly with the further addition of RTPF. Afterwards, the DIF ascended again with increasing RTPF content. The sudden increase in DIF when changing the RTPF content from $4.8 \mathrm{~kg} / \mathrm{m}^{3}$ to $9.6 \mathrm{~kg} / \mathrm{m}^{3}$ can be attributed to the low static compressive strength of RTPF96. As shown in Section 3.2, the static compressive strength of concrete was decreased by about $17.7 \%$ with the incorporation of RTPF of $9.6 \mathrm{~kg} / \mathrm{m}^{3}$. However, due to the strain rate effect, the dynamic compressive strength of RTPF96 was not significantly reduced (i.e. approximately 3.5-8.3\% lower than that of RTPF24 at various strain rates), which was comparable with that reinforced with $2.4 \mathrm{~kg} / \mathrm{m}^{3}$ (i.e. resulted in the highest improvement in dynamic compressive strength). Consequently, the DIF of RTPF96 was the highest among all FRC mixtures when the strain rate exceeded $60 \mathrm{~s}^{-1}$. A similar behaviour was presented in [34] that a descending trend for dynamic compressive strength of concrete with increasing rubber content but a reverse trend for DIF. This can be ascribed to the higher reduction ratio of static compressive strength compared to that of dynamic compressive strength. On the other hand, the optimal RTPF content was also found to be $2.4 \mathrm{~kg} / \mathrm{m}^{3}$ as RTPF24 reached the maximum DIF among all mixtures except RTPF96. For instance, the DIF of RTPF24 was enhanced by $14.8 \%$ compared to F0 at the strain rate of $120 \mathrm{~s}^{-1}$.

\subsubsection{Comparison between PPF and RTPF}

Fig. 16 shows the effects of PPF and RTPF on dynamic compressive strength of concrete mixtures. It can be observed that for the same fibre volume fraction $\left(0.1 \% \mathrm{~V}_{\mathrm{f}}\right)$, the dynamic compressive strength of PPF09 was comparable with that of RTPF12, where the difference between these two mixtures was found to be negligible when the strain rate was higher (no more than $2 \%$ difference). RTPF24 (i.e. $0.2 \% \mathrm{~V}_{\mathrm{f}}$ ) always exhibited higher dynamic compressive strength than PPF09, with the highest difference of $8.6 \%$ at the strain rate of $120 \mathrm{~s}^{-1}$. It can be concluded that replacing PPF by higher amount of RTPF can better improve the dynamic compressive strength of concrete. 
The influences of PPF and RTPF on energy absorption capacity of concrete mixtures are shown in Fig. 17. Similarly, RTPF12 did not present significant improvement on both fracture energy (Fig. 17a) and total energy (Fig. 17b) of concrete in comparison with the effect induced by PPF09. RTPF24 demonstrated consistently better performance in terms of energy absorption capacity than PPF09, which implies that with the substitution of $0.2 \% \mathrm{~V}_{\mathrm{f}}$ of RTPF rather than $0.1 \% \mathrm{~V}_{\mathrm{f}}$ of PPF the ductility of concrete can be improved. Fig. 18 shows a comparison of DIF for PPF09, RTPF12 and RTPF24. A similar trend can be observed that the DIF of RTPF24 was higher than that of PPF09 when the strain rate was higher than $40 \mathrm{~s}^{-1}$, where the highest difference was found to be $6.6 \%$ at the highest strain rate (i.e. $120 \mathrm{~s}^{-1}$ ).

Regarding the failure patterns (see Fig. 10), no clear differences were identified especially when the strain rate was higher than $74.8 \mathrm{~s}^{-1}$. When the strain rate was lower (in the range of 58.6 to $64.6 \mathrm{~s}^{-}$ ${ }^{1}$ ), several fracture parts were observed around the edge for RTPF12 (see Fig. 10i), but PPF09 demonstrated more complete appearance at the edge (see Fig. 10e). The SEM images presented in Figs. 19 and 20 can be used to explore the surface condition of fibres within the matrix after the SHPB test. As seen in Fig. 19a, RTPF was found to be ruptured after the fibre pull-out, where its ruptured end can be observed. Fibre bridging action plays an essential role in controlling the cracking through dissipating a large amount of energy, which enhances the ductility performance of the composite [67]. Fig. 19b shows that the RTPFs inside the matrix can bridge the fracture zones and thereby, enhancing the energy absorption capacity and reducing the crack width of FRC. By contrast, a de-bonding behaviour occurred between the PPF and the matrix (see Fig. 20a) and a distinct broken part can be observed on the surface of PPF (see Fig. 20b). If solely considering the surface condition of fibres, RTPF may have higher load-carrying capacity against dynamic loadings than PPF.

To sum up, under the same fibre volume fraction, both PPF and RTPF reinforced concrete mixtures presented better dynamic compressive behaviour than plain concrete (F0). However, PPF was found to be more efficient in absorbing energy than RTPF under the same fibre volume fraction. Furthermore, given the fact that RTPF (i.e. $8.7 \mathrm{~mm}$ averagely) used in this study was shorter than that of PPF (i.e. $19 \mathrm{~mm}$ ), which may affect its crack-controlling performance as long fibre tends to arrest the crack with a larger size and could be potentially sustained by a bigger load [4]. Thus, the replacement of PPF by higher volume fraction of RTPF (two times higher) in FRC is recommended in this study if considering dynamic compressive strength, energy absorption capacity and DIF.

\section{Conclusions}

In this study, the workability, static compressive strength and dynamic compressive properties of recycled tyre polymer fibre (RTPF) reinforced concrete with various fibre content (i.e., 1.2, 2.4, 4.8 and $9.6 \mathrm{~kg} / \mathrm{m}^{3}$ that are equivalent to $0.1 \%, 0.2 \%, 0.4 \%$ and $0.8 \% \mathrm{~V}_{\mathrm{f}}$ ) were experimentally investigated and compared with those without fibre reinforcement. In addition, the concrete mixture reinforced 
with $0.9 \mathrm{~kg} / \mathrm{m}^{3}$ (equivalent to $0.1 \% \mathrm{~V}_{\mathrm{f}}$ ) of polypropylene fibre (PPF) was prepared and compared with those reinforced with RTPF. Based on the experimental results, the main conclusions can be drawn as follows:

- The dynamic compressive properties including dynamic compressive strength and energy absorption capacity were improved with the incorporation of RTPF up to $2.4 \mathrm{~kg} / \mathrm{m}^{3}$ at various strain rates. With the further addition of RTPF (i.e. 4.8 and $9.6 \mathrm{~kg} / \mathrm{m}^{3}$ ), the influences tended to be insignificant. However, the workability and 28-d static compressive strength of concrete reinforced with RTPF were decreased by $8.1 \%$ to $62.2 \%$ and $5.8 \%$ to $17.7 \%$ respectively compared to those of concrete without fibre.

- All concrete mixtures were found to be sensitive to the strain rate. The dynamic compressive properties including dynamic compressive strength, ultimate strain, energy absorption capacity and DIF were enhanced with the increase of strain rate. The fitted dynamic increase factor (DIF) curves with correlation coefficients greater than 0.9 were derived for all mixtures, which can be used to reliably describe the strong relationship between DIF and strain rate.

- Considering the workability, static compressive strength and dynamic compressive properties, the optimal RTPF content was recommended as $2.4 \mathrm{~kg} / \mathrm{m}^{3}$, as RTPF2 4 showed the most development in dynamic compressive strength (ranging from 6.6\% to $12.9 \%$ ), fracture energy (ranging from $10.4 \%$ to $54.4 \%$ ) and total energy (ranging from $6.8 \%$ to $26.4 \%$ ) among all mixtures. Moreover, it exhibited acceptable workability and static compressive strength.

- $0.1 \% \mathrm{~V}_{\mathrm{f}}$ of PPF can be substituted with higher fibre volume fraction of RTPF (approximately two times higher) in terms of workability, and static and dynamic compressive properties. In addition, the SEM images suggest that the RTPF probably exhibits higher load-carrying capacity in comparison with PPF. However, a further study on the mechanism of bond between the RTPF and the matrix is still required.

\section{Acknowledgement}

The authors gratefully acknowledge the financial support by the State Key Laboratory of Silicate Materials for Architectures (Wuhan University of Technology) (No. SYSJJ2017-08 and No. SYSJJ2018-08), Research Fund of Liaoning Natural Science Foundation (No. 20170540304 and No. 20170540303), National Training Program of Innovation and Entrepreneurship for Undergraduates (No. 201810145047) and Fundamental Research Funds for the Central Universities (No. N170104023).

\section{References}

[1] H.R. Pakravan, M. Latifi, M. Jamshidi, Hybrid short fiber reinforcement system in concrete: A review, Construction and Building Materials 142 (2017) 280-294. 
[2] A. Sivakumar, M. Santhanam, Mechanical properties of high strength concrete reinforced with metallic and non-metallic fibres, Cement and Concrete Composites 29(8) (2007) 603-608.

[3] M.-J. Kim, D.-Y. Yoo, S. Kim, M. Shin, N. Banthia, Effects of fiber geometry and cryogenic condition on mechanical properties of ultra-high-performance fiber-reinforced concrete, Cement and Concrete Research 107 (2018) 30-40.

[4] Z. Wu, C. Shi, W. He, D. Wang, Static and dynamic compressive properties of ultra-high performance concrete (UHPC) with hybrid steel fiber reinforcements, Cement and Concrete Composites 79 (2017) 148-157.

[5] H. Zhang, L. Wang, K. Zheng, T.J. Bakura, P.G. Totakhil, Research on compressive impact dynamic behavior and constitutive model of polypropylene fiber reinforced concrete, Construction and Building Materials 187 (2018) 584-595.

[6] P.S. Song, S. Hwang, B.C. Sheu, Strength properties of nylon- and polypropylene-fiber-reinforced concretes, Cement and Concrete Research 35(8) (2005) 1546-1550.

[7] A. Alavi Nia, M. Hedayatian, M. Nili, V.A. Sabet, An experimental and numerical study on how steel and polypropylene fibers affect the impact resistance in fiber-reinforced concrete, International Journal of Impact Engineering 46 (2012) 62-73.

[8] H. Kasagani, C.B.K. Rao, Effect of graded fibers on stress strain behaviour of Glass Fiber Reinforced Concrete in tension, Construction and Building Materials 183 (2018) 592-604.

[9] M. Mastali, A. Dalvand, A.R. Sattarifard, The impact resistance and mechanical properties of reinforced self-compacting concrete with recycled glass fibre reinforced polymers, Journal of Cleaner Production 124 (2016) 312-324.

[10] C. Scheffler, S. Zhandarov, E. Mäder, Alkali resistant glass fiber reinforced concrete: Pull-out investigation of interphase behavior under quasi-static and high rate loading, Cement and Concrete Composites 84 (2017) 19-27.

[11] M. Şahmaran, V.C. Li, Durability of mechanically loaded engineered cementitious composites under highly alkaline environments, Cement and Concrete Composites 30(2) (2008) 72-81.

[12] M. Şahmaran, V.C. Li, De-icing salt scaling resistance of mechanically loaded engineered cementitious composites, Cement and Concrete Research 37(7) (2007) 1035-1046.

[13] K. Yu, L. Li, J. Yu, Y. Wang, J. Ye, Q. Xu, Direct tensile properties of engineered cementitious composites: A review, Construction and Building Materials 165 (2018) 346-362.

[14] M. Şahmaran, E. Özbay, H.E. Yücel, M. Lachemi, V.C. Li, Frost resistance and microstructure of Engineered Cementitious Composites: Influence of fly ash and micro poly-vinyl-alcohol fiber, Cement and Concrete Composites 34(2) (2012) 156-165. 
[15] Q.S. Banyhussan, G. Yıldırım, E. Bayraktar, S. Demirhan, M. Şahmaran, Deflection-hardening hybrid fiber reinforced concrete: The effect of aggregate content, Construction and Building Materials 125 (2016) 41-52.

[16] M. Şahmaran, E. Özbay, H. Yücel, M. Lachemi, V. Li, Effect of Fly Ash and PVA Fiber on Microstructural Damage and Residual Properties of Engineered Cementitious Composites Exposed to High Temperatures, 2011.

[17] H. Ma, E. Herbert, M. Ohno, V.C. Li, Scale-linking model of self-healing and stiffness recovery in Engineered Cementitious Composites (ECC), Cement and Concrete Composites 95 (2019) 1-9.

[18] O. Onuaguluchi, N. Banthia, Scrap tire steel fiber as a substitute for commercial steel fiber in cement mortar: Engineering properties and cost-benefit analyses, Resources, Conservation and Recycling 134 (2018) 248-256.

[19] K. Adalberth, Energy use during the life cycle of single-unit dwellings: Examples, Build. Environ. 32(4) (1997) 321-329.

[20] W. Gao, T. Ariyama, T. Ojima, A. Meier, Energy impacts of recycling disassembly material in residential buildings, Energy and Buildings 33(6) (2001) 553-562.

[21] B.S. Thomas, R.C. Gupta, A comprehensive review on the applications of waste tire rubber in cement concrete, Renewable and Sustainable Energy Reviews 54 (2016) 1323-1333.

[22] S. Ramarad, M. Khalid, C.T. Ratnam, A.L. Chuah, W. Rashmi, Waste tire rubber in polymer blends: A review on the evolution, properties and future, Progress in Materials Science 72 (2015) 100-140.

[23] J.A.O. Barros, C. Frazão, A. Caggiano, P. Folino, E. Martinelli, H. Xargay, Z. Zamanzadeh, L. Lourenço, Cementitious Composites Reinforced with Recycled Fibres, in: J.A.O. Barros, L. Ferrara, E. Martinelli (Eds.), Recent Advances on Green Concrete for Structural Purposes: The contribution of the EU-FP7 Project EnCoRe, Springer International Publishing, Cham, 2017, pp. 141-195.

[24] M.A. Aiello, F. Leuzzi, G. Centonze, A. Maffezzoli, Use of steel fibres recovered from waste tyres as reinforcement in concrete: pull-out behaviour, compressive and flexural strength, Waste Manag 29(6) (2009) 1960-70.

[25] K. Neocleous, H. Tlemat, K. Pilakoutas, Design issues for concrete reinforced with steel fibers, including fibers recovered from used tires, Journal of Materials in Civil Engineering 18 (2008) 677685.

[26] G. Centonze, M. Leone, M.A. Aiello, Steel fibers from waste tires as reinforcement in concrete: A mechanical characterization, Construction and Building Materials 36 (2012) 46-57.

[27] D. Bjegovic, A. Baricevic, S. Lakusic, D. Damjanovic, I. Duvnjak, Positive Interaction of Industrial and Recycled Steel Fibres in Fibre Reinforced Concrete, Journal of Civil Engineering and Management 19(Supplement_1) (2014) S50-S60. 
[28] Z. Zamanzadeh, L. Lourenço, J. Barros, Recycled Steel Fibre Reinforced Concrete failing in bending and in shear, Construction and Building Materials 85 (2015) 195-207.

[29] A. Caggiano, P. Folino, C. Lima, E. Martinelli, M. Pepe, On the mechanical response of Hybrid Fiber Reinforced Concrete with Recycled and Industrial Steel Fibers, Construction and Building Materials 147 (2017) 286-295.

[30] Ł. Skarżyński, J. Suchorzewski, Mechanical and fracture properties of concrete reinforced with recycled and industrial steel fibers using Digital Image Correlation technique and X-ray micro computed tomography, Construction and Building Materials 183 (2018) 283-299.

[31] F. Grzymski, M. Musiał, T. Trapko, Mechanical properties of fibre reinforced concrete with recycled fibres, Construction and Building Materials 198 (2019) 323-331.

[32] C. Frazão, B. Díaz, J. Barros, J.A. Bogas, F. Toptan, An experimental study on the corrosion susceptibility of Recycled Steel Fiber Reinforced Concrete, Cement and Concrete Composites 96 (2019) 138-153.

[33] M.A. Aiello, F. Leuzzi, Waste tyre rubberized concrete: properties at fresh and hardened state, Waste Manag 30(8-9) (2010) 1696-704.

[34] F. Liu, G. Chen, L. Li, Y. Guo, Study of impact performance of rubber reinforced concrete, Construction and Building Materials 36 (2012) 604-616.

[35] A.F. Angelin, R.C.C. Lintz, L.A. Gachet-Barbosa, W.R. Osório, The effects of porosity on mechanical behavior and water absorption of an environmentally friendly cement mortar with recycled rubber, Construction and Building Materials 151 (2017) 534-545.

[36] B.S. Thomas, R.C. Gupta, V.J. Panicker, Recycling of waste tire rubber as aggregate in concrete: durability-related performance, Journal of Cleaner Production 112 (2016) 504-513.

[37] B.S. Thomas, R. Chandra Gupta, Properties of high strength concrete containing scrap tire rubber, Journal of Cleaner Production 113 (2016) 86-92.

[38] R. Si, J. Wang, S. Guo, Q. Dai, S. Han, Evaluation of laboratory performance of selfconsolidating concrete with recycled tire rubber, Journal of Cleaner Production 180 (2018) 823-831. [39] R. Si, S. Guo, Q. Dai, Durability performance of rubberized mortar and concrete with NaOHSolution treated rubber particles, Construction and Building Materials 153 (2017) 496-505.

[40] A. Baričević, M. Jelčić Rukavina, M. Pezer, N. Štirmer, Influence of recycled tire polymer fibers on concrete properties, Cement and Concrete Composites 91 (2018) 29-41.

[41] A. Baricevic, M. Pezer, M. Jelcic Rukavina, M. Serdar, N. Stirmer, Effect of polymer fibers recycled from waste tires on properties of wet-sprayed concrete, Construction and Building Materials 176 (2018) 135-144. 
[42] M. Serdar, A. Baričević, M. Jelčić Rukavina, M. Pezer, D. Bjegović, N. Štirmer, Shrinkage Behaviour of Fibre Reinforced Concrete with Recycled Tyre Polymer Fibres, International Journal of Polymer Science 2015 (2015) 1-9.

[43] S.-S. Huang, H. Angelakopoulos, K. Pilakoutas, I. Burgess, Reused tyre polymer fibre for firespalling mitigation, Applications of Structural Fire Engineering, 2015.

[44] O. Onuaguluchi, N. Banthia, Durability performance of polymeric scrap tire fibers and its reinforced cement mortar, Materials and Structures 50(2) (2017).

[45] S.B. Kim, N.H. Yi, H.Y. Kim, J.-H.J. Kim, Y.-C. Song, Material and structural performance evaluation of recycled PET fiber reinforced concrete, Cement and Concrete Composites 32(3) (2010) 232-240.

[46] Z. Sun, Q. Xu, Microscopic, physical and mechanical analysis of polypropylene fiber reinforced concrete, Materials Science and Engineering: A 527(1) (2009) 198-204.

[47] H. Toutanji, S. McNeil, Z. Bayasi, Chloride permeability and impact resistance of polypropylene-fiber-reinforced silica fume concrete, Cement and Concrete Research 28(7) (1998) 961-968.

[48] Testing methods of workability of normal concrete, GB/T50080-2016, China Building Materials Academy, China, 2016.

[49] Testing methods of mechanical properties of normal concrete, GB/T50081-2002, China Building Materials Academy, China 2002.

[50] Y. Hao, H. Hao, Dynamic compressive behaviour of spiral steel fibre reinforced concrete in split Hopkinson pressure bar tests, Construction and Building Materials 48 (2013) 521-532.

[51] J. Xiao, L. Li, L. Shen, C.S. Poon, Compressive behaviour of recycled aggregate concrete under impact loading, Cement and Concrete Research 71 (2015) 46-55.

[52] M. Yiping, H. Shisheng, Some problems existed in dynamic compressive test of concrete, Experimental Mechanics (in Chinese) 18(1) (2003) 108-112.

[53] L. Weimin, X. Jinyu, Q. Yi, L. Qing, The mechanical properties of carbon fibre reinforced concrete under impact loading, Civil Engineering Acaademic Journal (in Chinese) (2) (2009) 24-30. [54] W. Chen, B. Song, Split Hopkinson (Kolsky) Bar: Design, Testing and Applications, 2011.

[55] D.J. Frew, M.J. Forrestal, W. Chen, Pulse shaping techniques for testing brittle materials with a split hopkinson pressure bar, Experimental Mechanics 42(1) (2002) 93-106.

[56] K.S. Vecchio, F. Jiang, Improved Pulse Shaping to Achieve Constant Strain Rate and Stress Equilibrium in Split-Hopkinson Pressure Bar Testing, Metallurgical and Materials Transactions A 38(11) (2007) 2655-2665.

[57] M. Serdar, A. Baricevic, S. Lakušić, D. Bjegovic, Special purpose concrete products from waste tyre recyclates, Gradevinar 65(9) (2013) 793-801. 
[58] A. Benazzouk, O. Douzane, K. Mezreb, M. Quéneudec, Physico-mechanical properties of aerated cement composites containing shredded rubber waste, Cem. Concr. Compos. 28(7) (2006) 650-657.

[59] H. Zhang, B. Wang, A. Xie, Y. Qi, Experimental study on dynamic mechanical properties and constitutive model of basalt fiber reinforced concrete, Construction and Building Materials 152 (2017) 154-167.

[60] D.M. Cotsovos, M.N. Pavlović, Numerical investigation of concrete subjected to compressive impact loading. Part 1: A fundamental explanation for the apparent strength gain at high loading rates, Computers \& Structures 86(1) (2008) 145-163.

[61] D.M. Cotsovos, M.N. Pavlović, Numerical investigation of concrete subjected to compressive impact loading. Part 2: Parametric investigation of factors affecting behaviour at high loading rates, Computers \& Structures 86(1) (2008) 164-180.

[62] C.A. Ross, Moisture and strain rate effects on concrete strength, ACI Mater. J. 93(3) (1996) 293300.

[63] Q. Fu, D. Niu, J. Zhang, D. Huang, Y. Wang, M. Hong, L. Zhang, Dynamic compressive mechanical behaviour and modelling of basalt-polypropylene fibre-reinforced concrete, Archives of Civil and Mechanical Engineering 18(3) (2018) 914-927.

[64] X. Hou, S. Cao, W. Zheng, Q. Rong, G. Li, Experimental study on dynamic compressive properties of fiber-reinforced reactive powder concrete at high strain rates, Engineering Structures 169 (2018) 119-130.

[65] L. Jin, R. Zhang, Y. Tian, G. Dou, X. Du, Experimental investigation on static and dynamic mechanical properties of steel fiber reinforced ultra-high-strength concretes, Construction and Building Materials 178 (2018) 102-111.

[66] M.K. Lee, B.I.G. Barr, An overview of the fatigue behaviour of plain and fibre reinforced concrete, Cement and Concrete Composites 26(4) (2004) 299-305.

[67] N. Ranjbar, S. Talebian, M. Mehrali, C. Kuenzel, H.S. Cornelis Metselaar, M.Z. Jumaat, Mechanisms of interfacial bond in steel and polypropylene fiber reinforced geopolymer composites, Composites Science and Technology 122 (2016) 73-81. 


\section{Figures:}
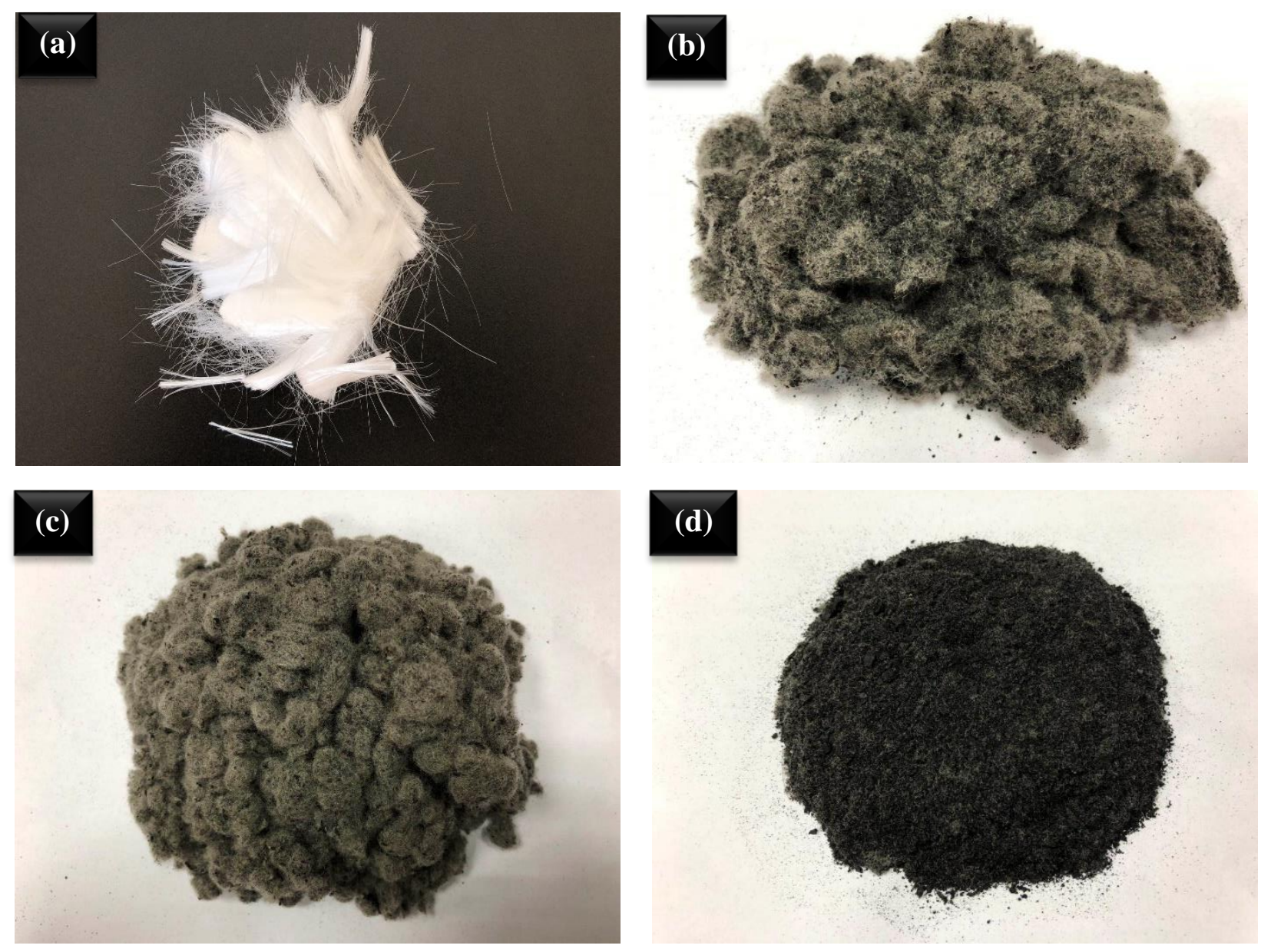

Fig. 1. Fibres used in this study: (a) PPF; (b) original RTPF; (c) cleaned RTPF (56.8 wt.\% of original RTPF); and (d) rubber granules (43.2 wt.\% of original RTPF) 
(a)
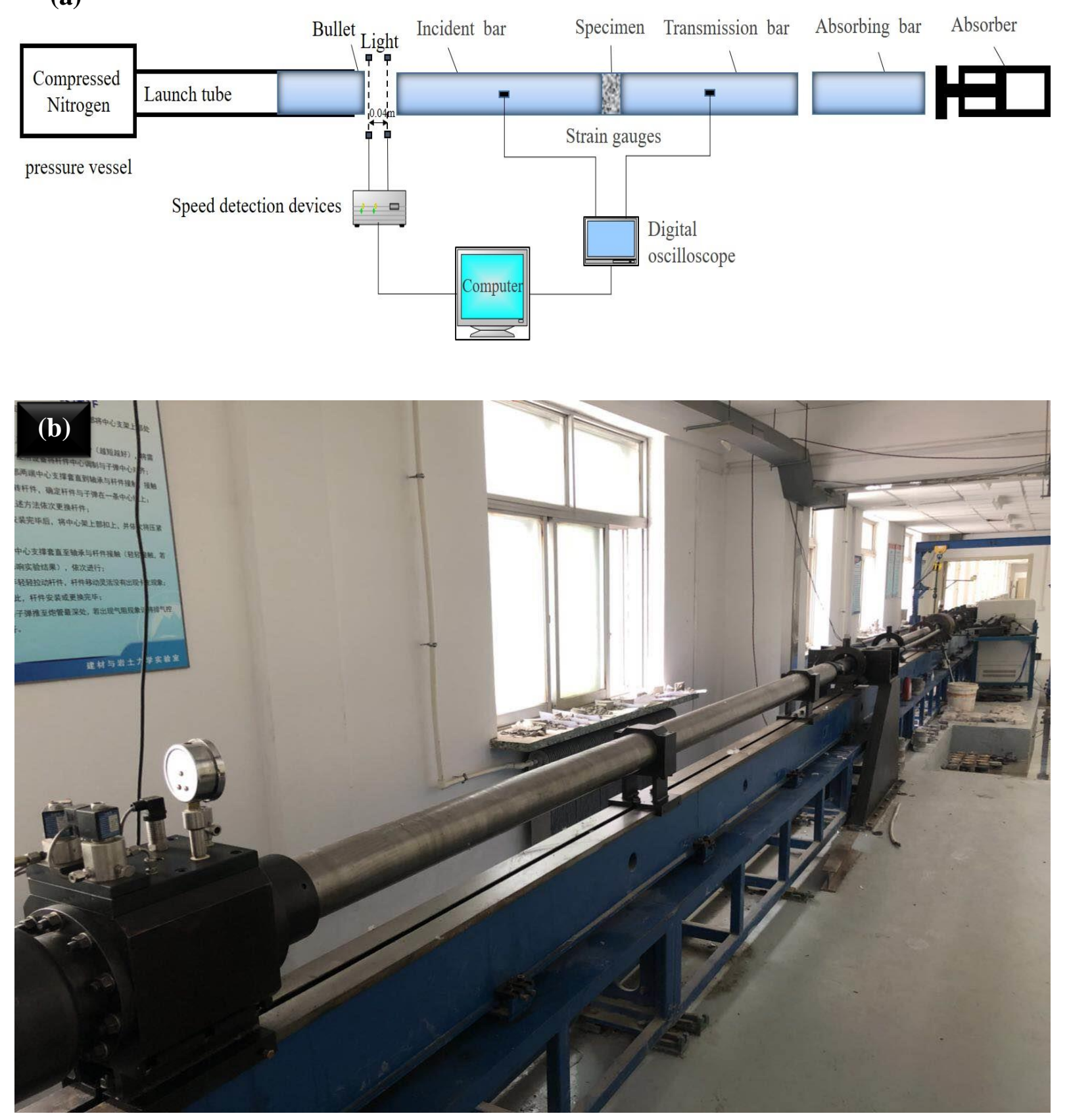

Fig. 2. Splitting Hopkinson pressure bar (SHPB) testing system: (a) schematic diagram; (b) picture 


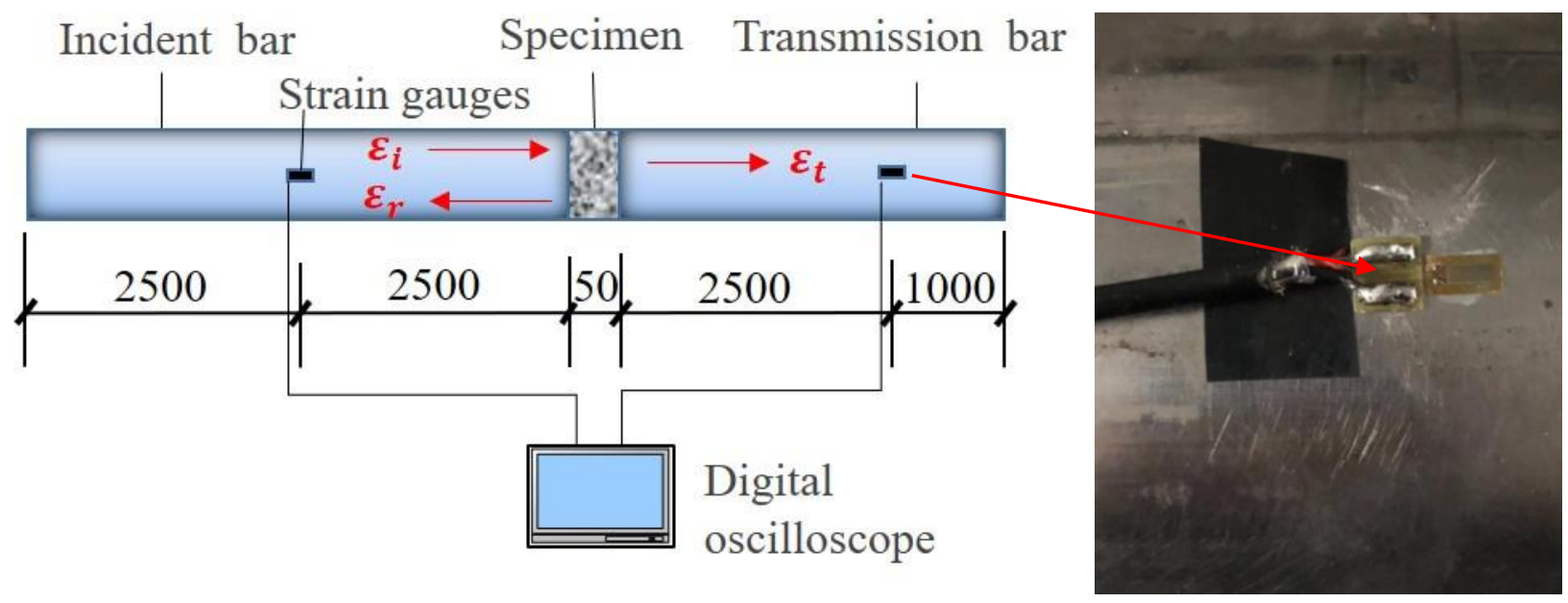

Fig. 3. Strain gauges used in SHPB testing system: (a) schematic diagram showing the positions of strain gauges; (b) picture 

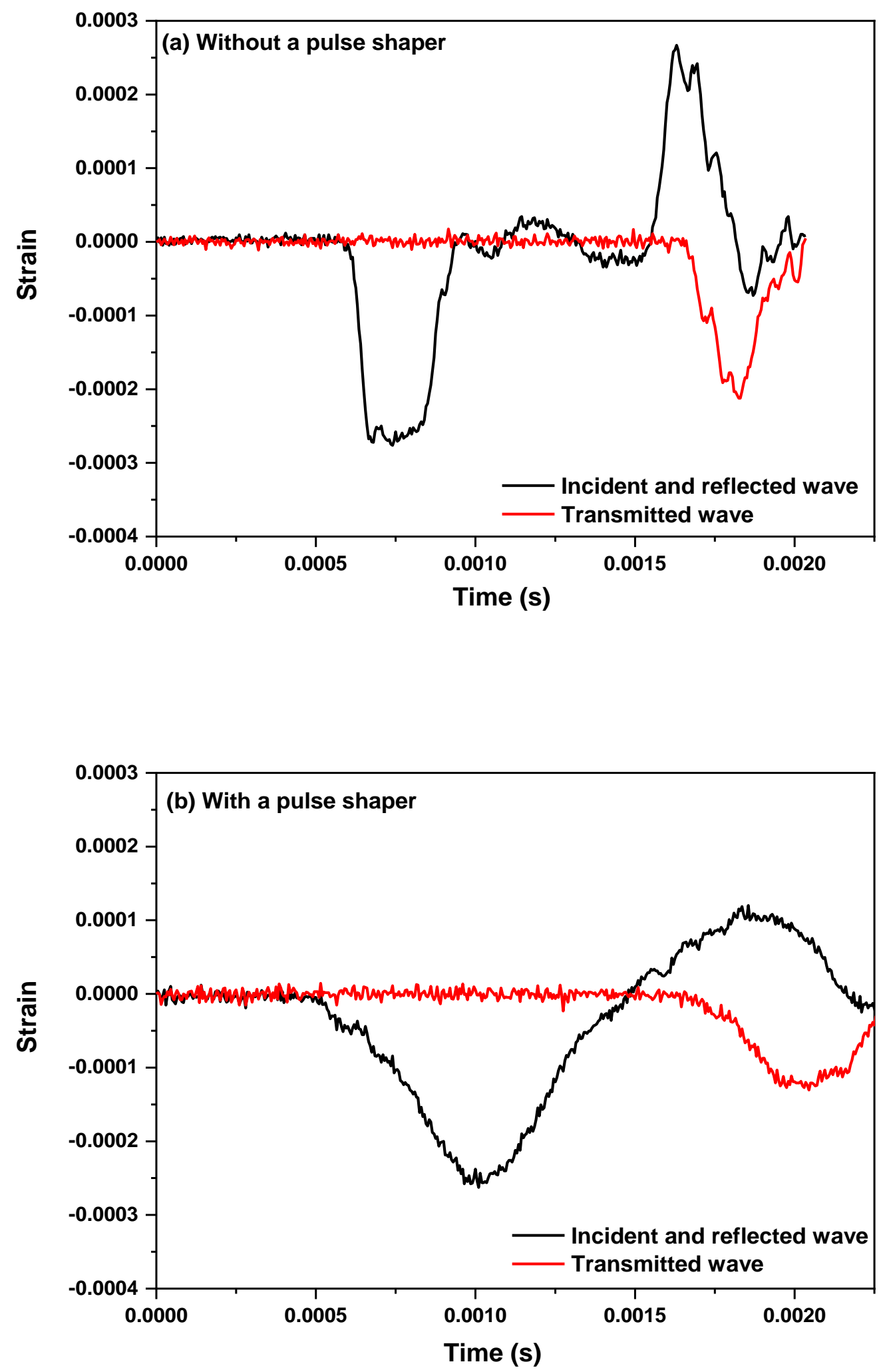

Fig. 4. Typical waveforms of incident, reflected and transmitted pulses: (a) without a pulse shaper; (b) with a pulse shaper 


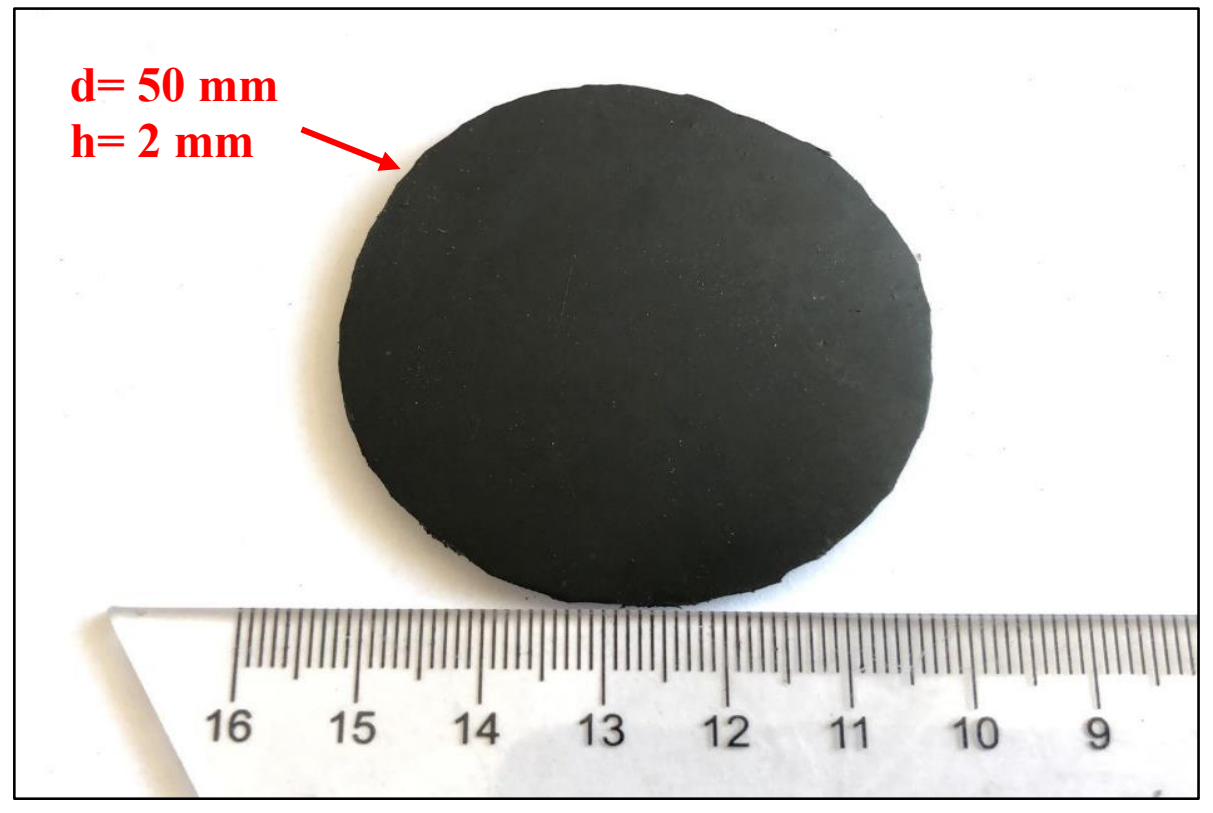

Fig. 5. Rubber-made pulse shaper used in the SHPB test

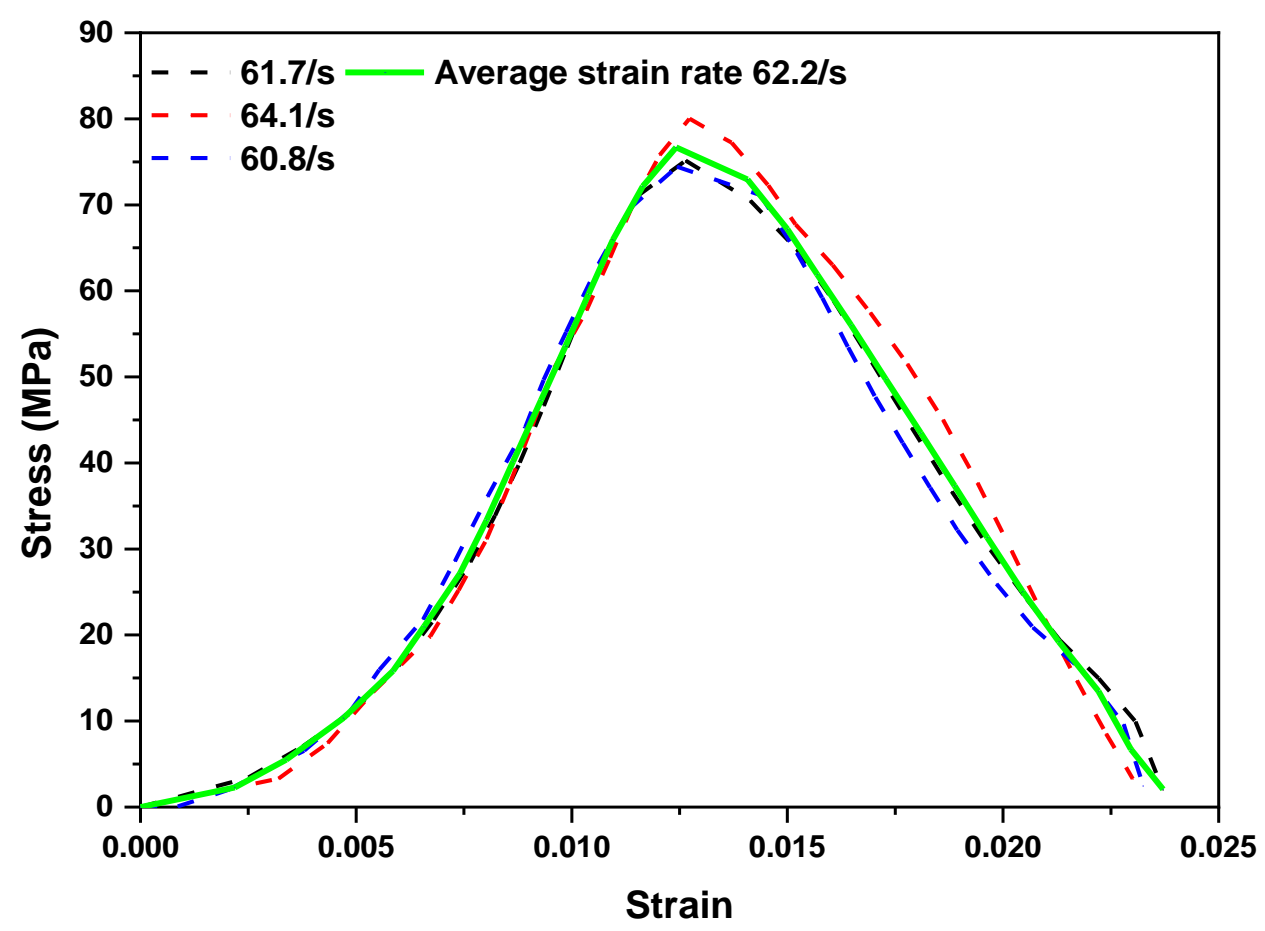

Fig. 6. Example of obtaining the dynamic compressive stress-strain curve 


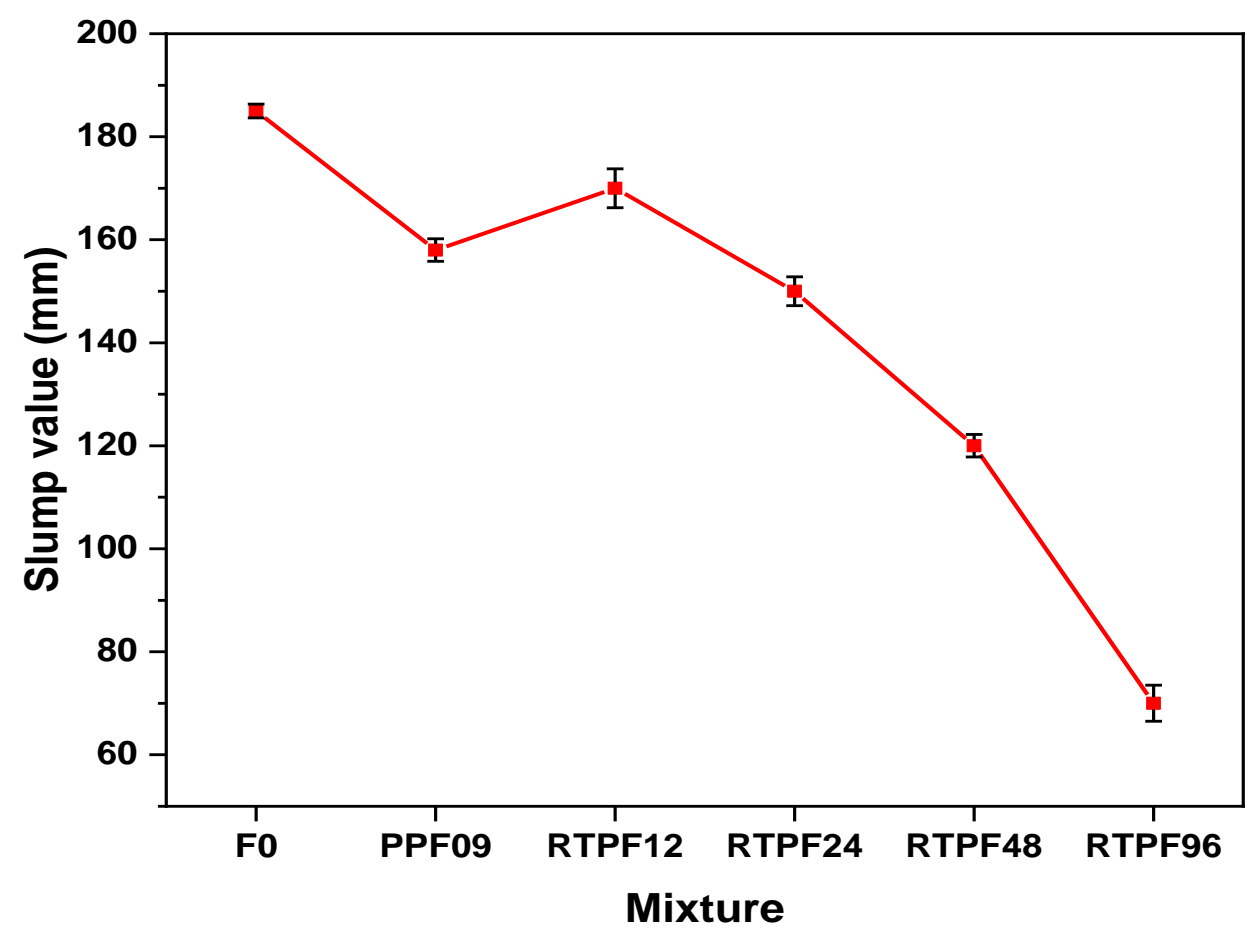

Fig. 7. Effect of PP and RTPF fibres on slump value of concrete mixtures

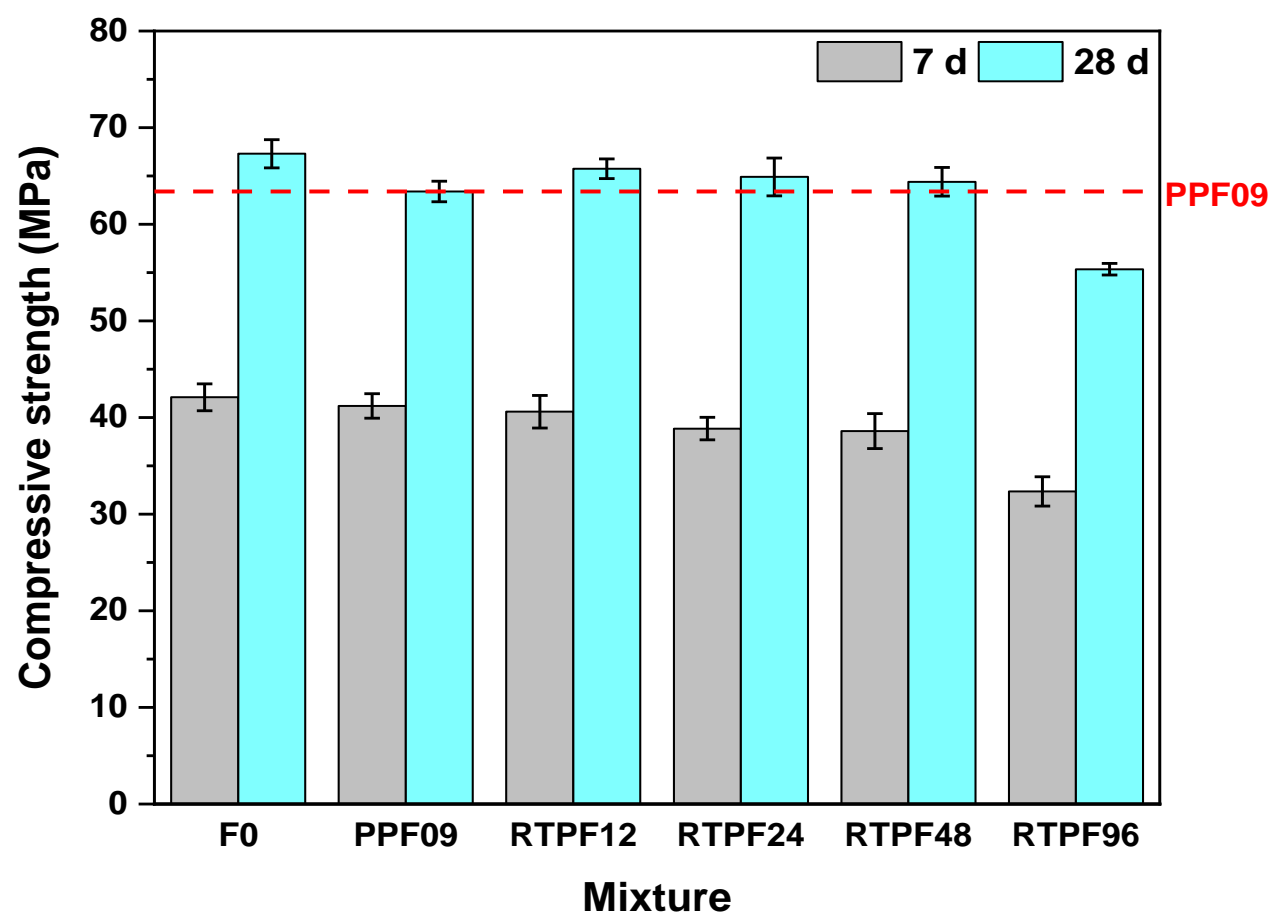

Fig. 8. Compressive strength of all mixtures at $7 \mathrm{~d}$ and $28 \mathrm{~d}$ 

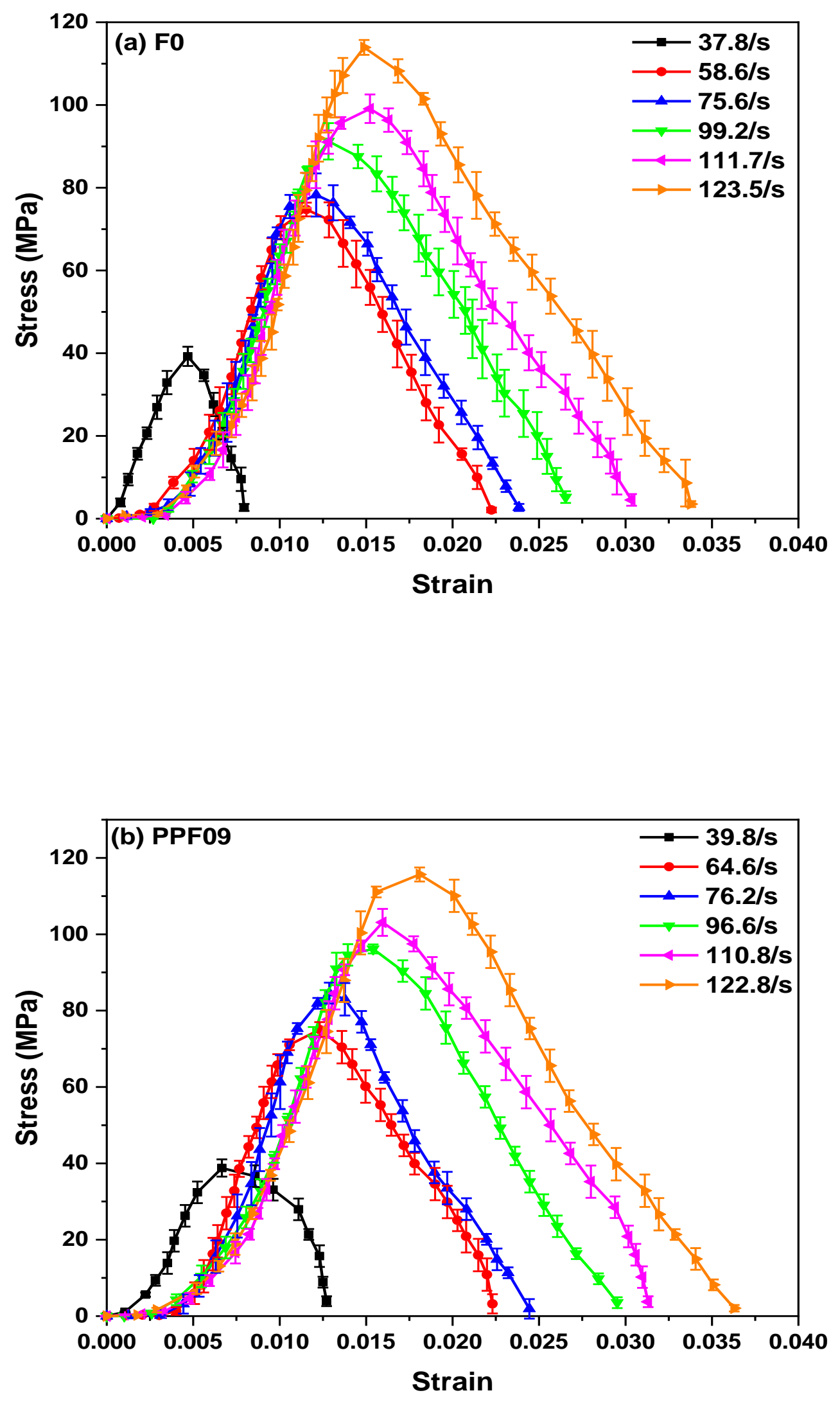

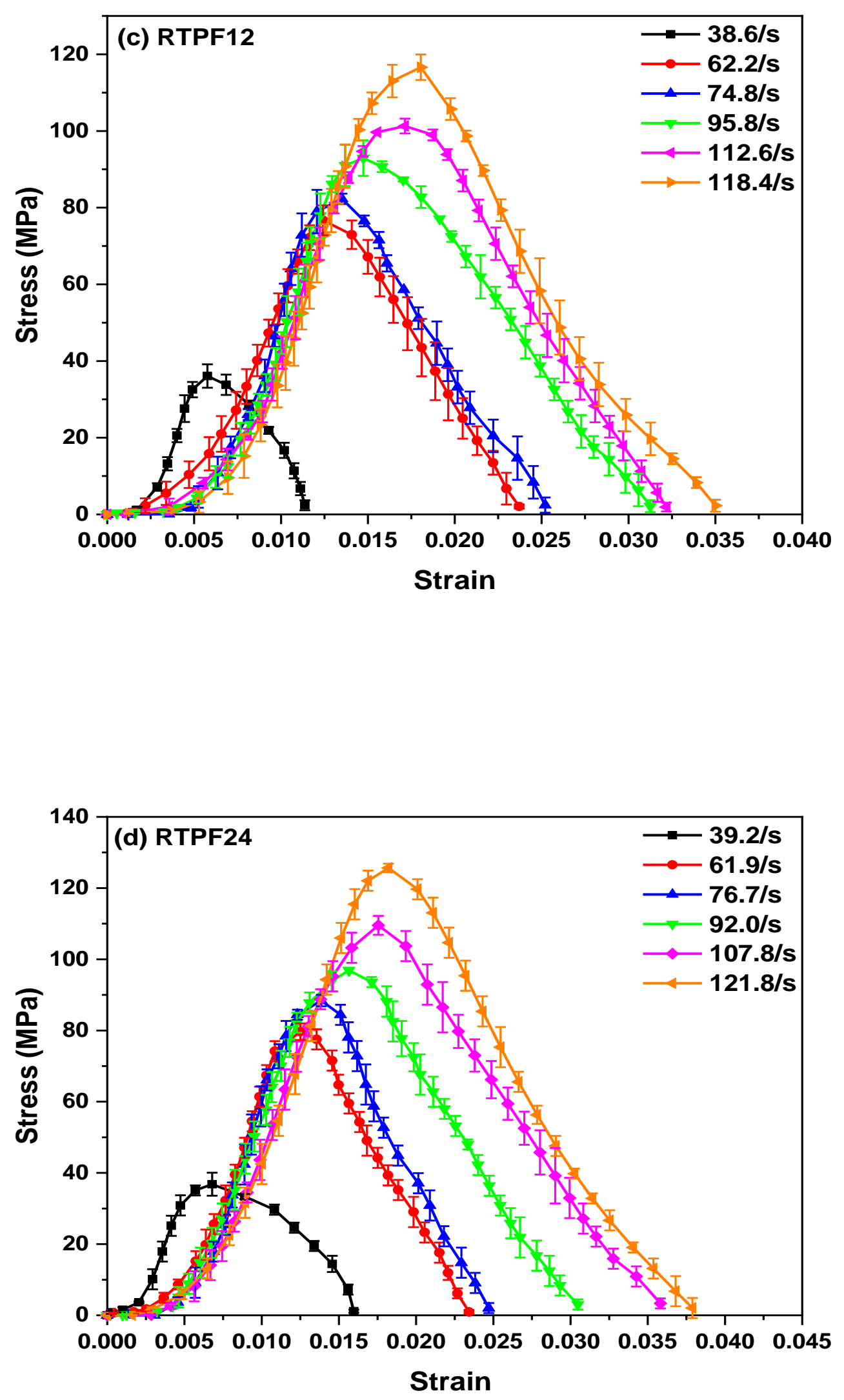

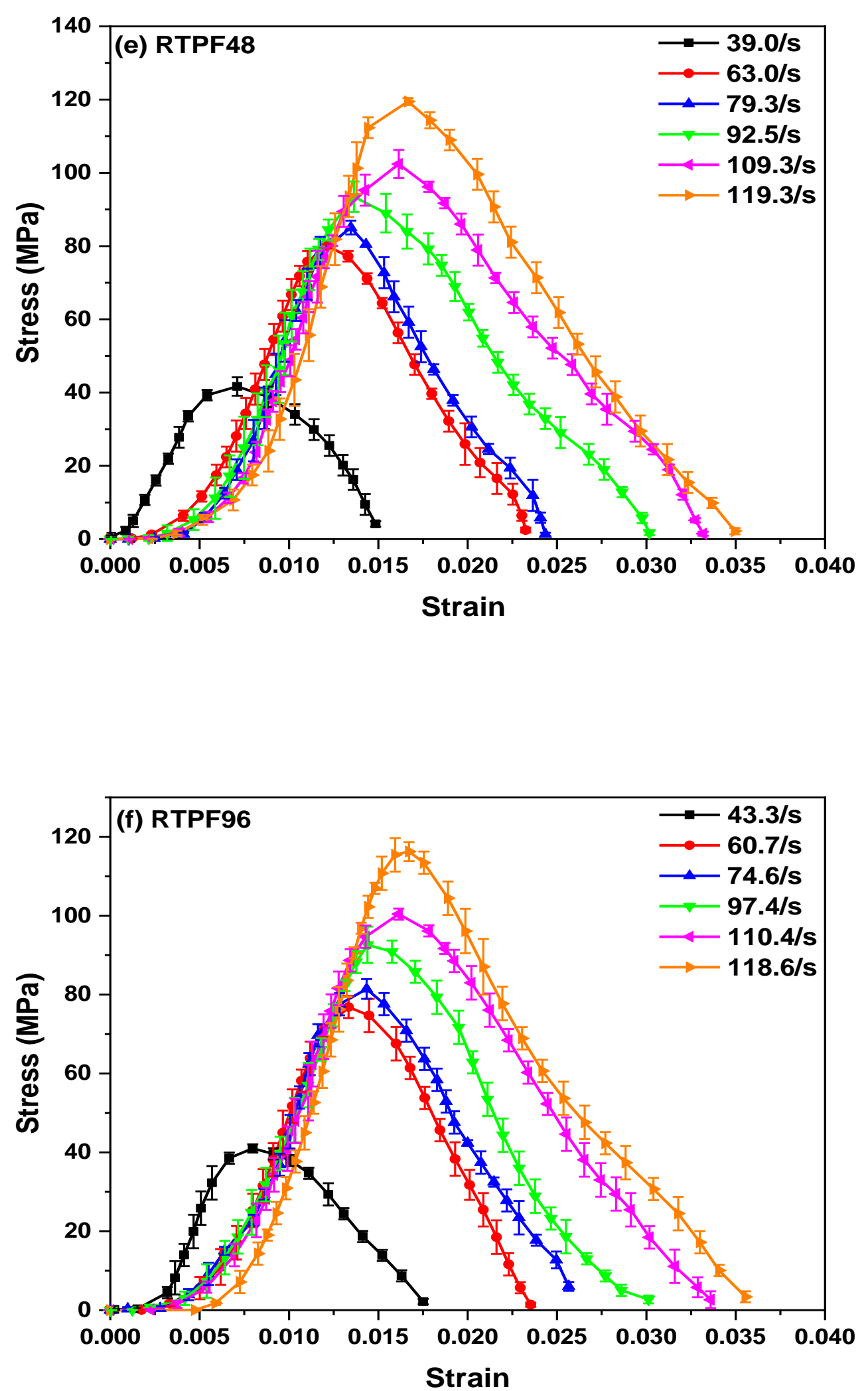

Fig. 9. Effect of different strain rates on dynamic compressive stress-strain curves of: (a) F0; (b) PPF09; (c) RTPF12; (d) RTPF24; (e) RTPF48; and (f) RTPF96 


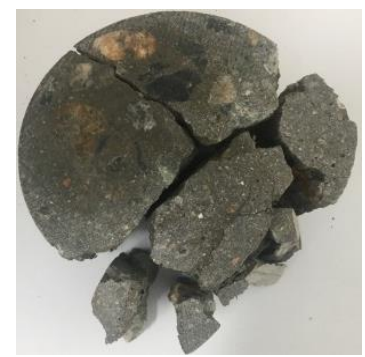

(a) F0 $\left(58.6 \mathrm{~s}^{-1}\right)$

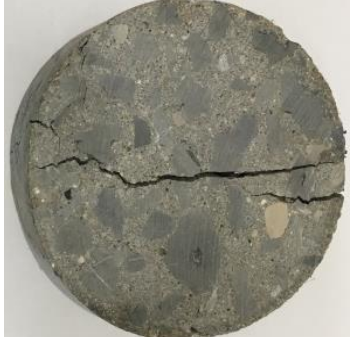

(e) PPF09 $\left(64.6 \mathrm{~s}^{-1}\right)$

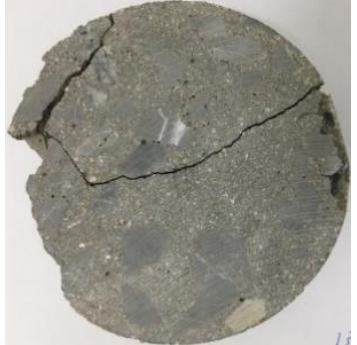

(i) RTPF12 $\left(62.2 \mathrm{~s}^{-1}\right)$

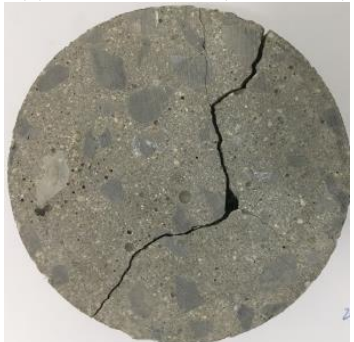

(m) RTPF24 $\left(61.9 \mathrm{~s}^{-1}\right)$

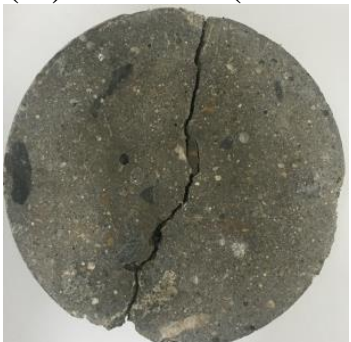

(q) RTPF48 $\left(63.0 \mathrm{~s}^{-1}\right)$

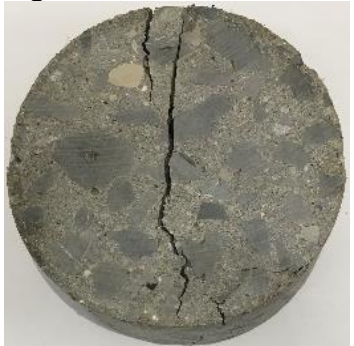

(u) RTPF96 $\left(60.7 \mathrm{~s}^{-1}\right)$

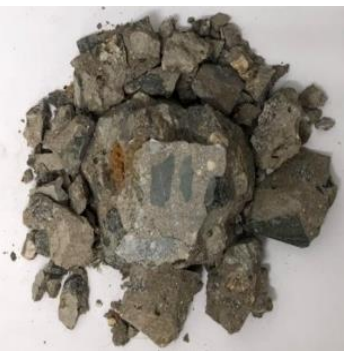

(b) F0 $\left(75.6 \mathrm{~s}^{-1}\right)$

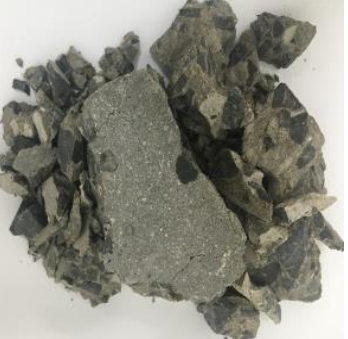

(f) PPF09 $\left(76.2 \mathrm{~s}^{-1}\right)$

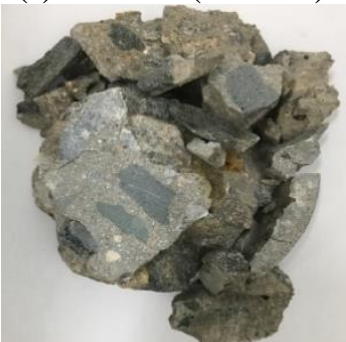

(j) RTPF12 $\left(74.8 \mathrm{~s}^{-1}\right)$

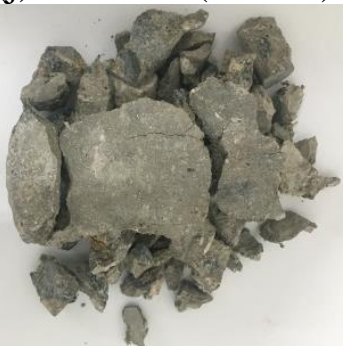

) (n) RTPF24 $\left(76.7 \mathrm{~s}^{-1}\right)$

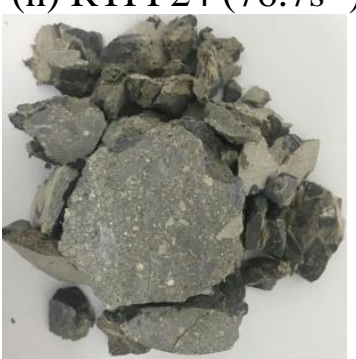

) (r) RTPF48 $\left(79.3 \mathrm{~s}^{-1}\right)$
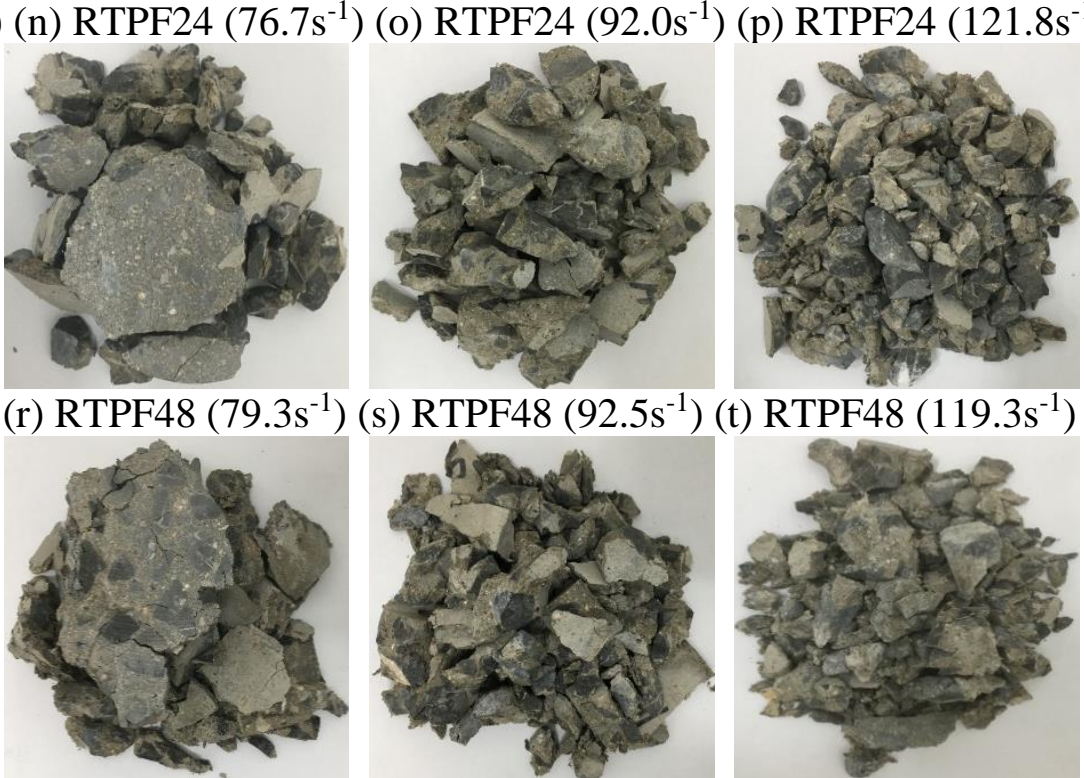

(c) F0 $\left(99.2 \mathrm{~s}^{-1}\right)$

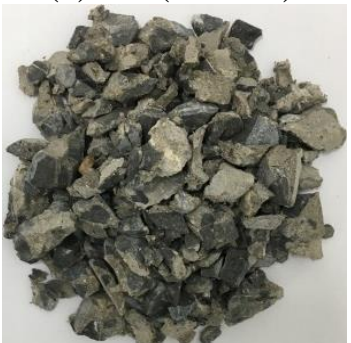

(g) PPF09 $\left(96.6 \mathrm{~s}^{-1}\right)$

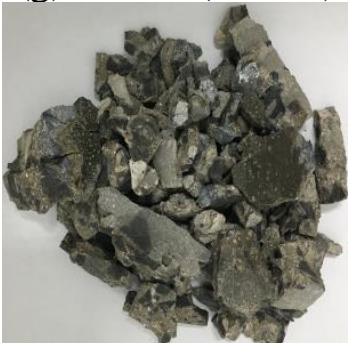

(h) PPF09 $\left(122.8 \mathrm{~s}^{-1}\right)$

(k) RTPF12 $\left(95.8 \mathrm{~s}^{-1}\right)$ (1) RTPF12 $\left(118.4 \mathrm{~s}^{-1}\right)$
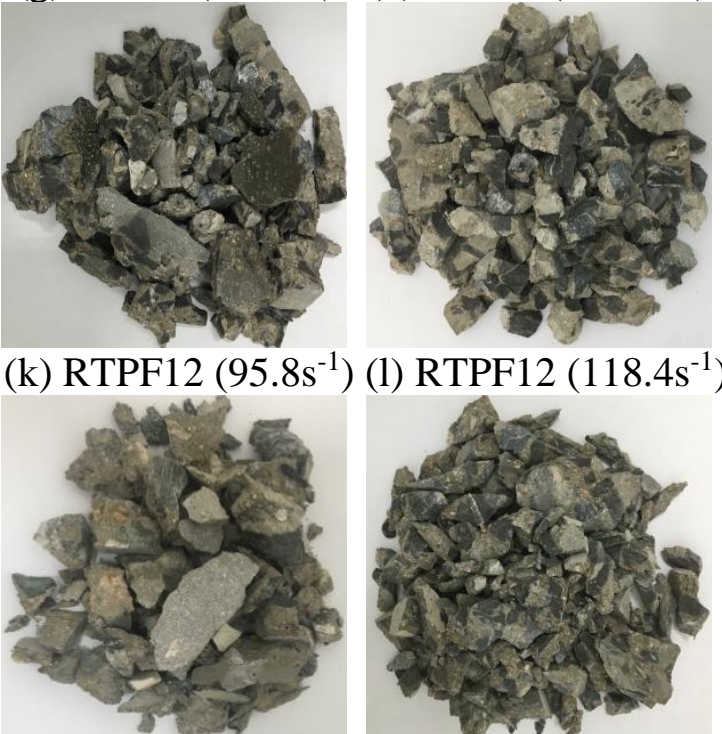

(t) RTPF48 $\left(119.3 \mathrm{~s}^{-1}\right)$

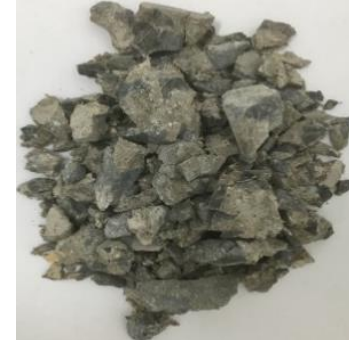

(v) RTPF96 (74.6s $\left.{ }^{-1}\right)(w)$ RTPF96 $\left(97.4 s^{-1}\right)(x)$ RTPF96 $\left(118.6 \mathrm{~s}^{-1}\right)$

Fig. 10. Failure patterns of all mixtures at different strain rates 


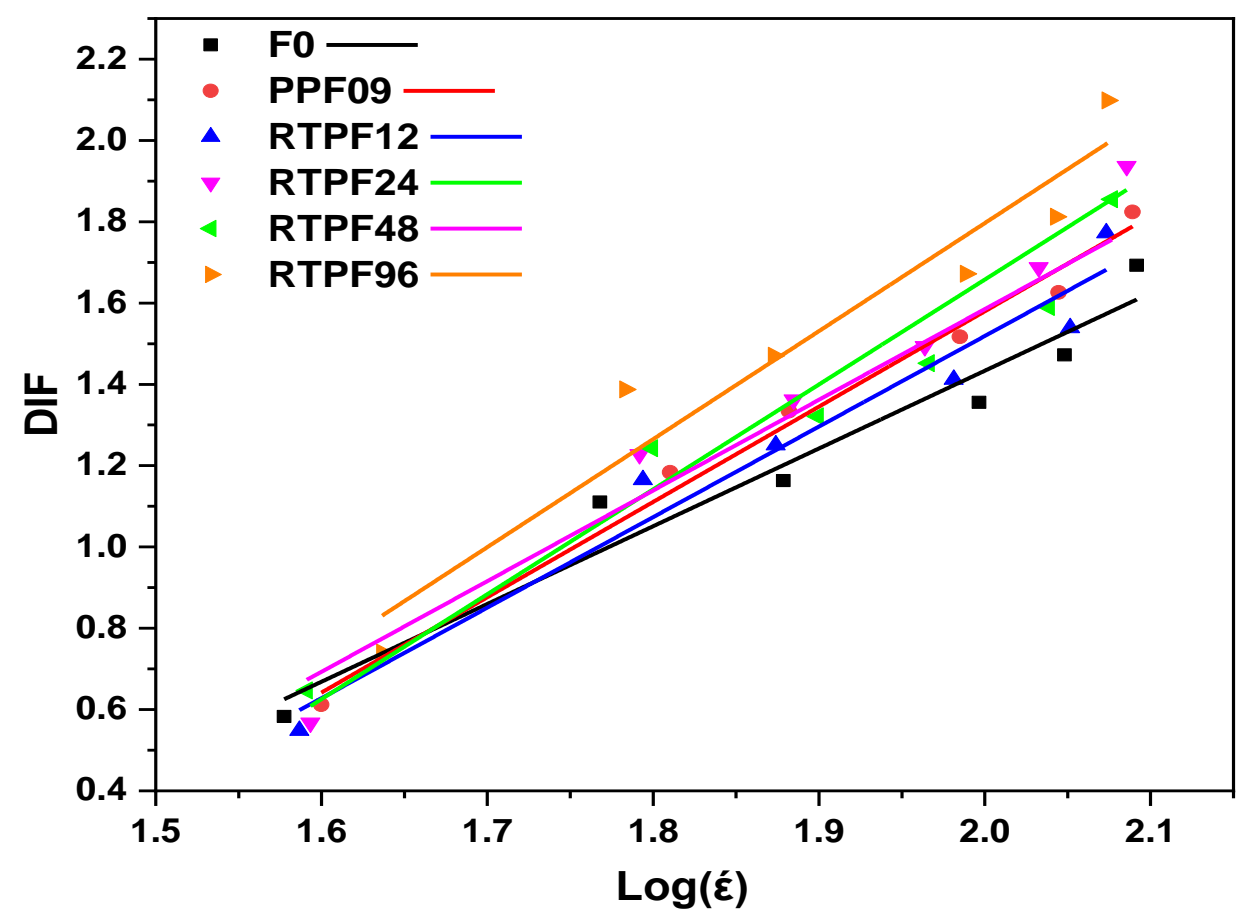

Fig. 11. Relationship between DIF and strain rate for all concrete mixtures

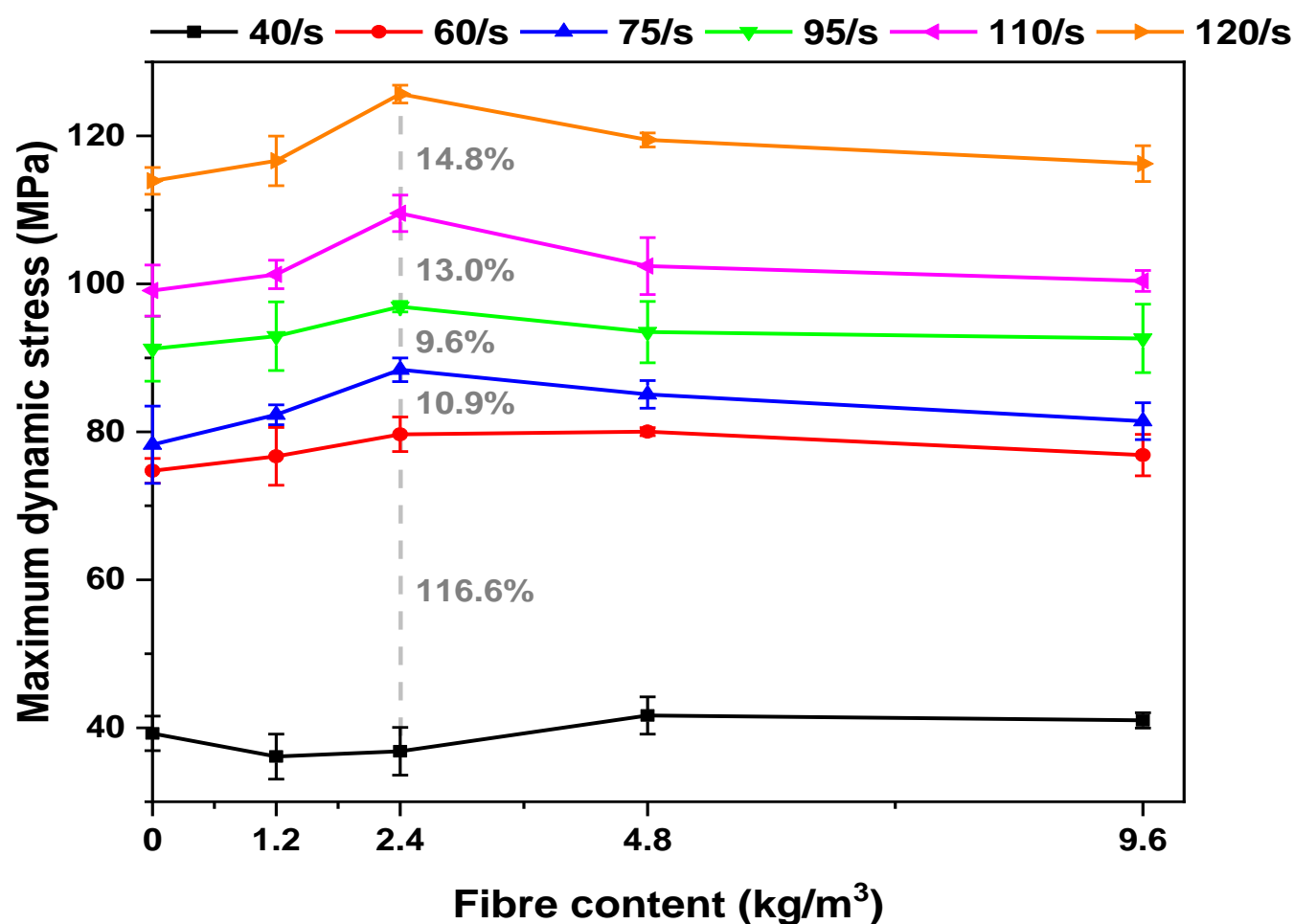

Fig. 12. Effect of RTPF content on dynamic compressive strength of concrete mixtures 

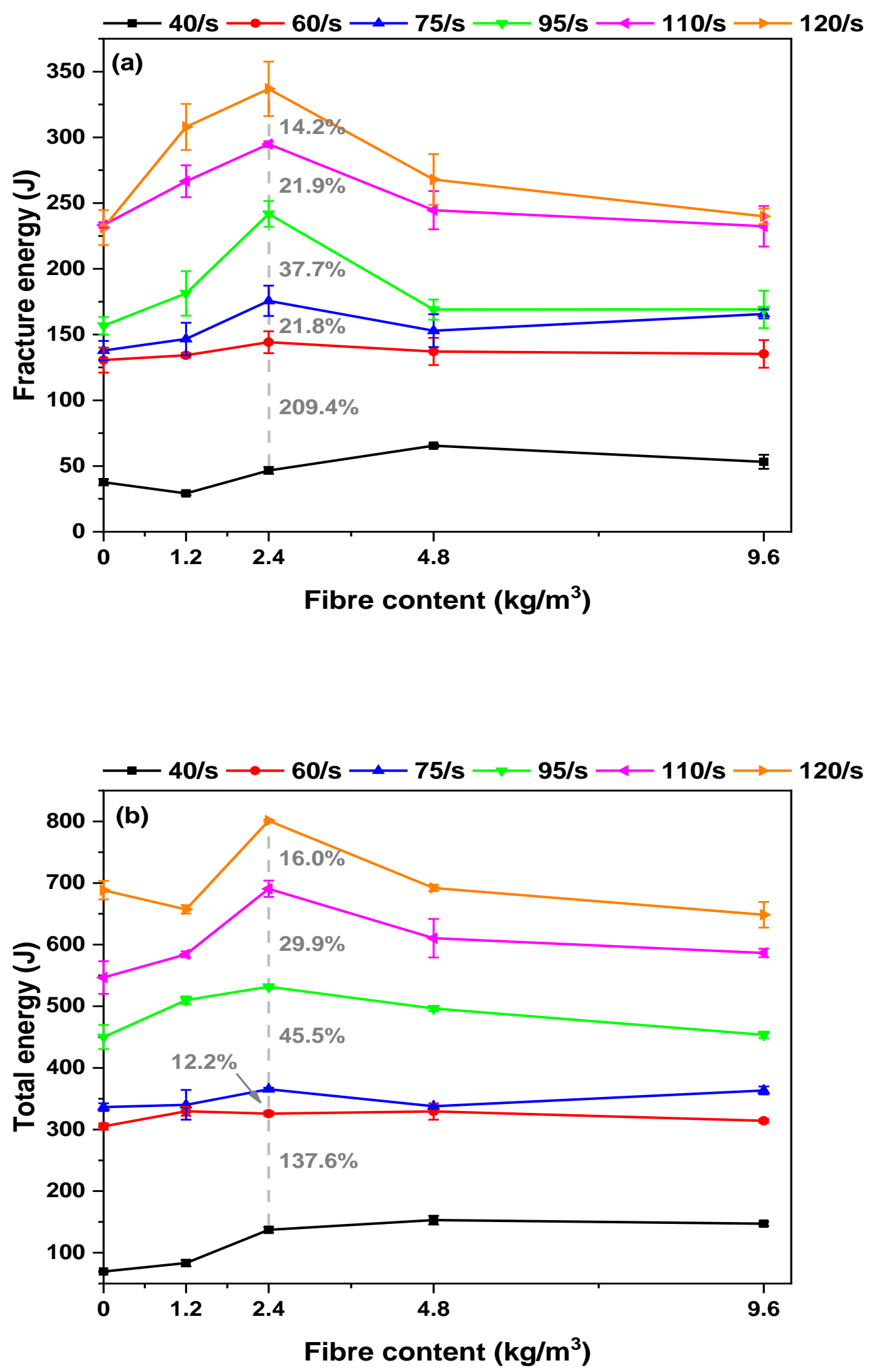

Fig. 13. Effect of RTPF content on energy absorption capacity of concrete mixtures 


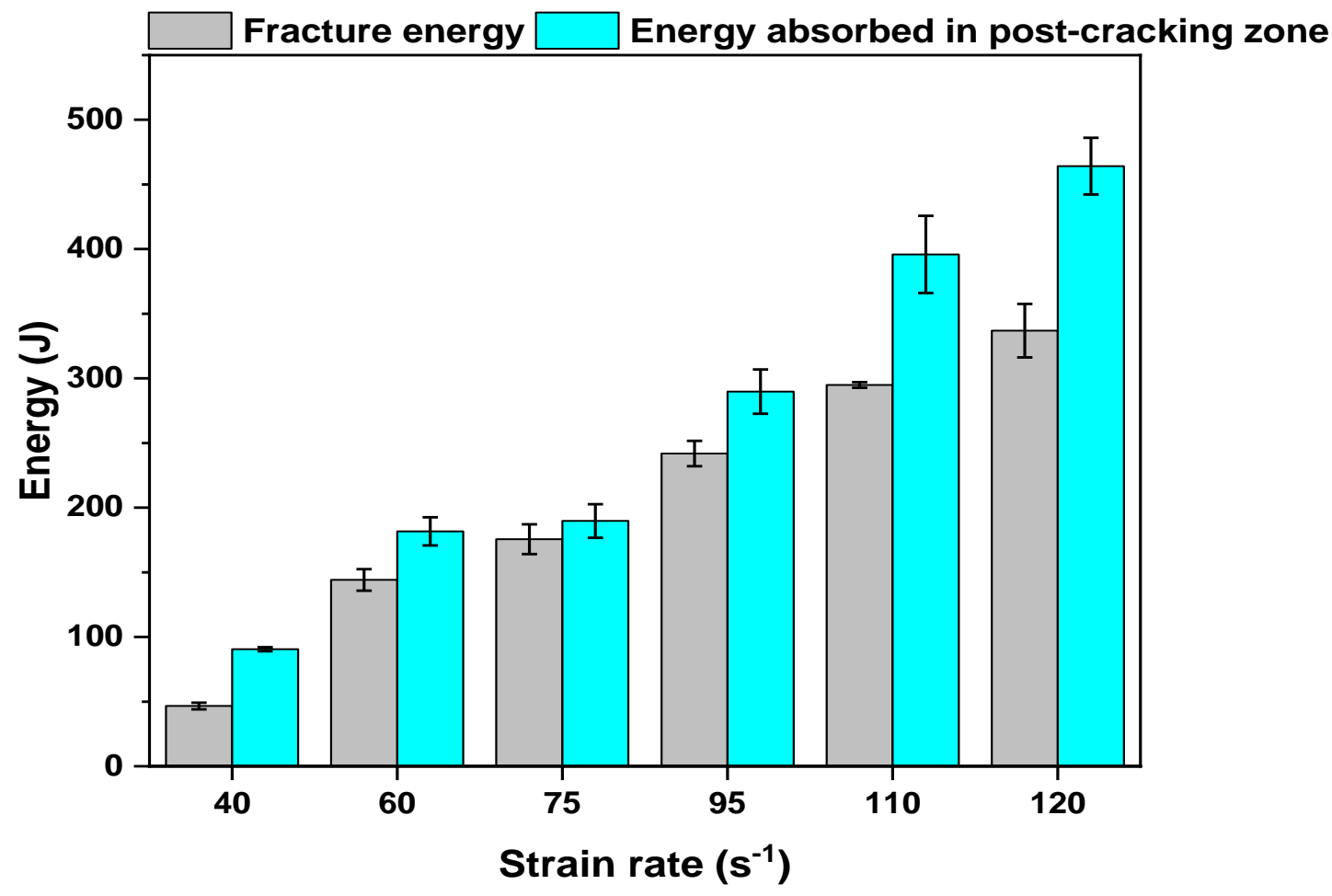

Fig. 14. Energy absorption capacity of RTPF24 in two different stages

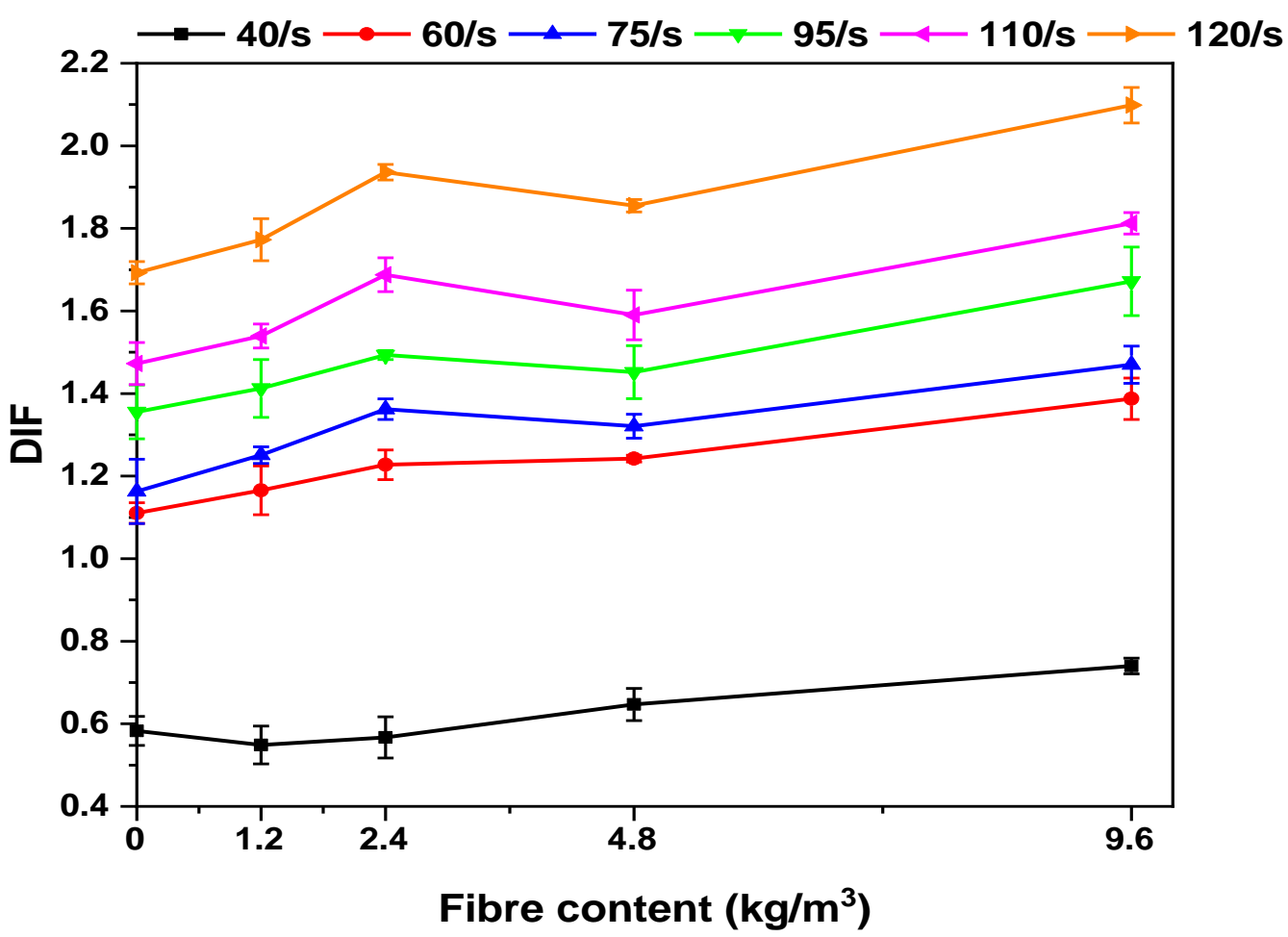

Fig. 15. Effect of RTPF content on DIF of concrete mixtures 


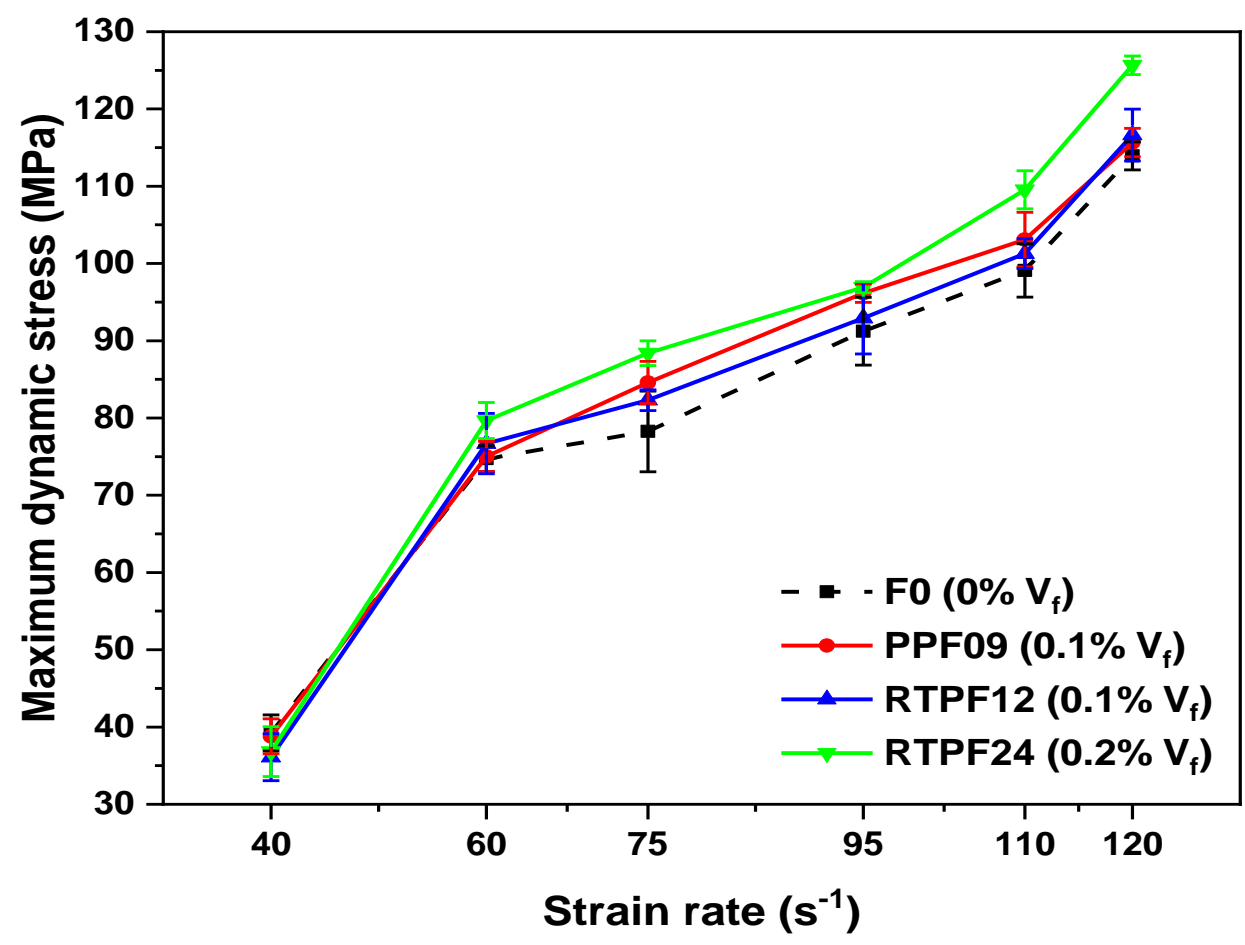

Fig. 16. Comparison of dynamic compressive strength among PPF09, RTPF12 and RTPF24

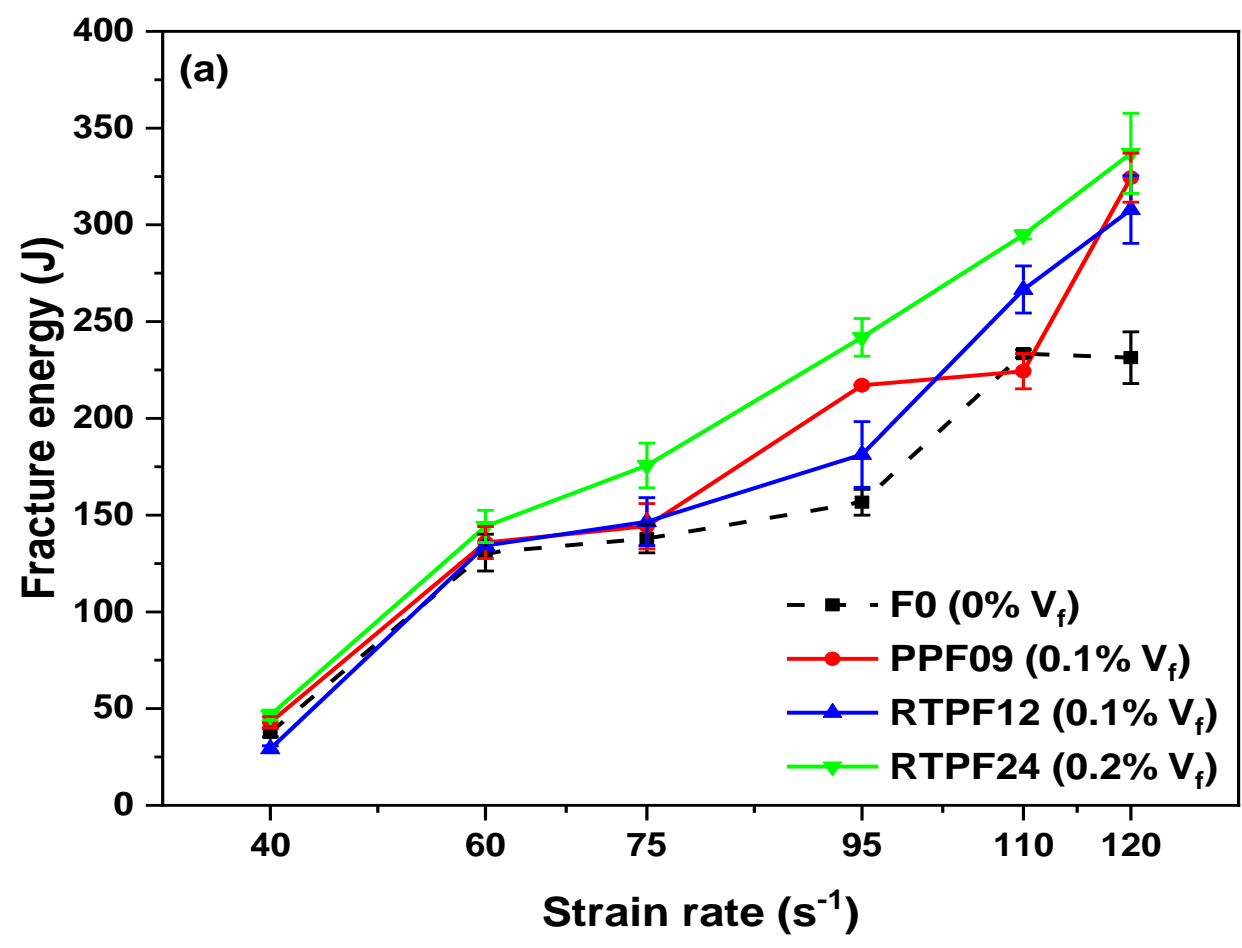




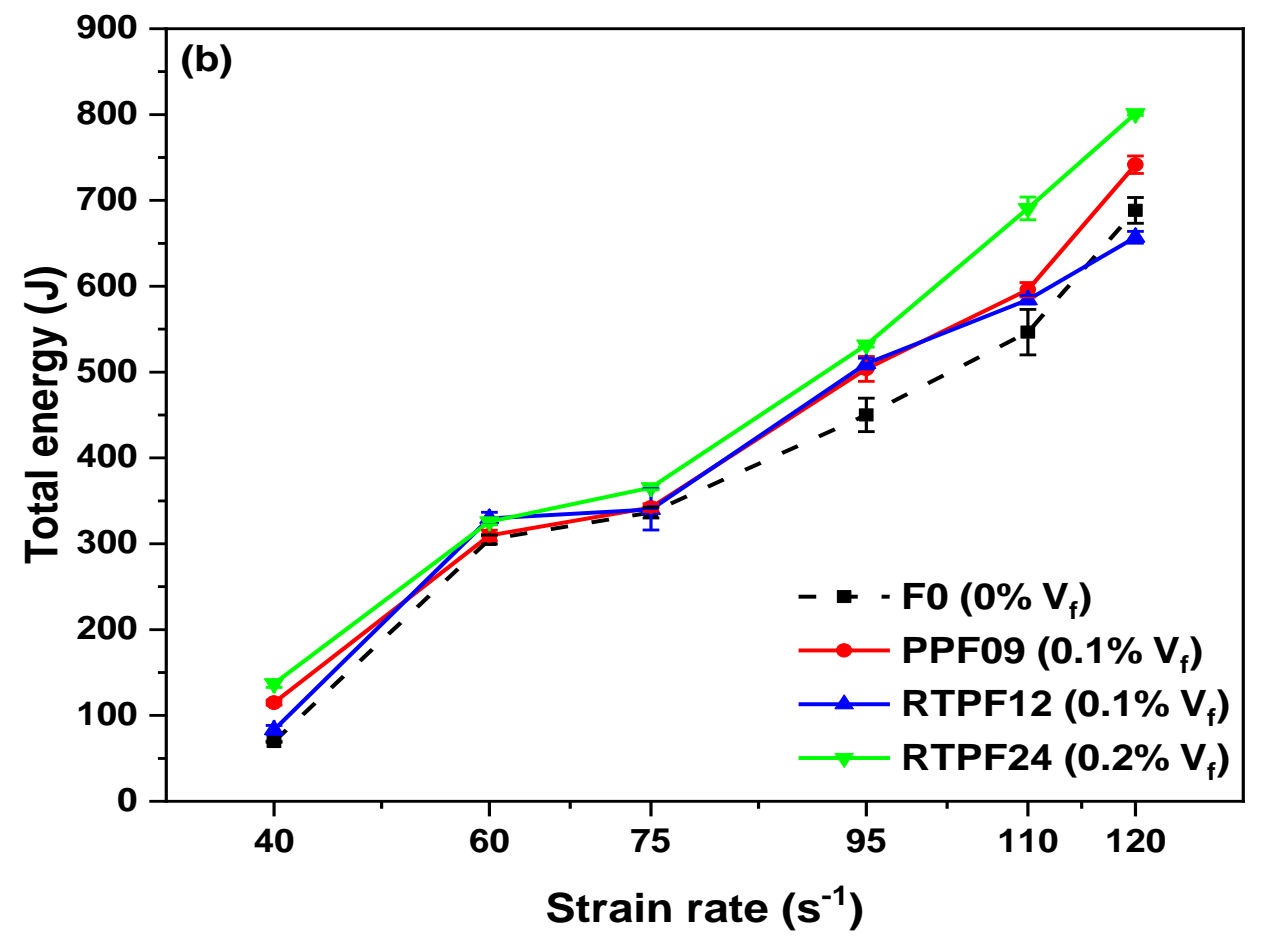

Fig. 17. Comparison of energy absorption capacity among PPF09, RTPF12 and RTPF24

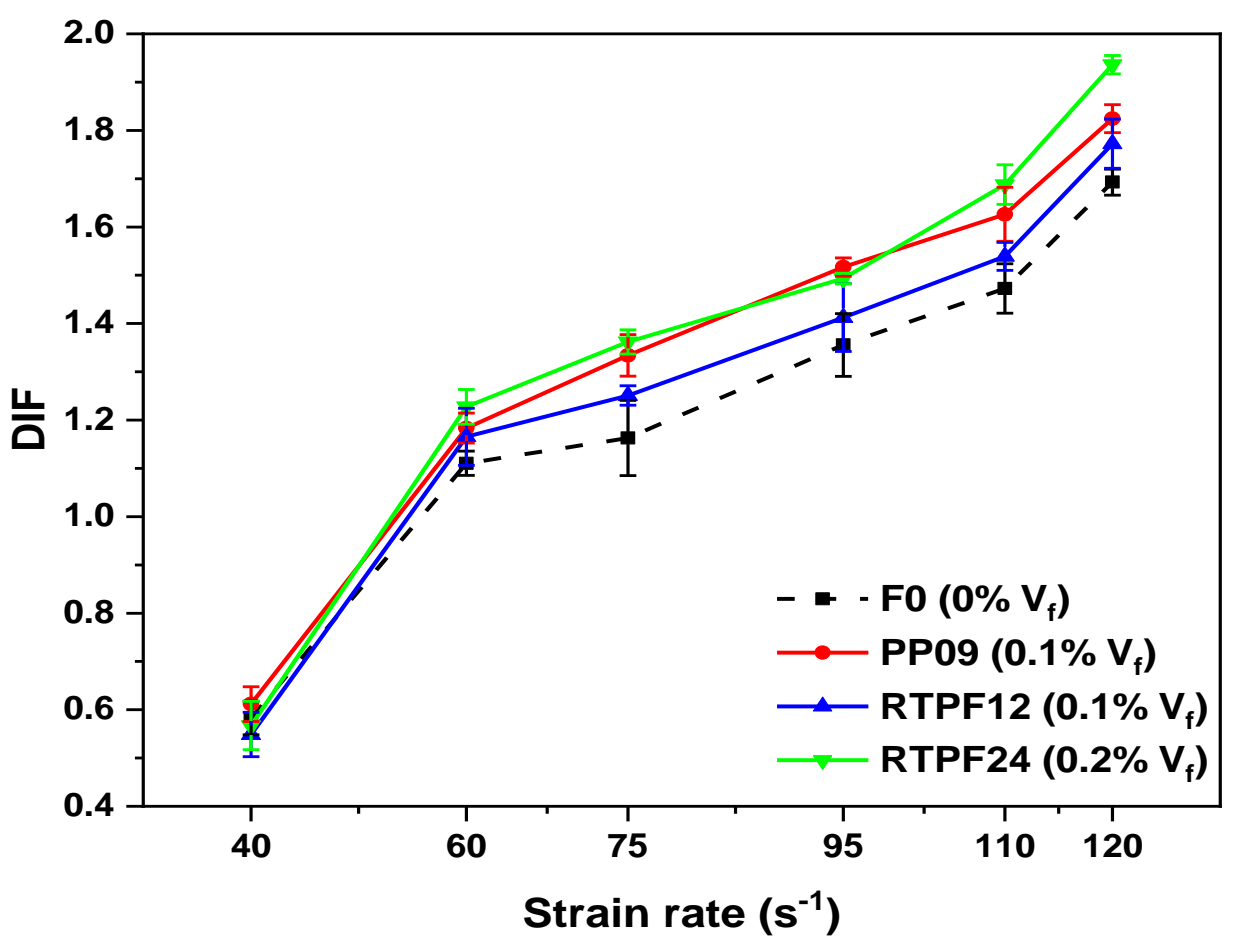

Fig. 18. Comparison of DIF among PPF09, RTPF12 and RTPF24 

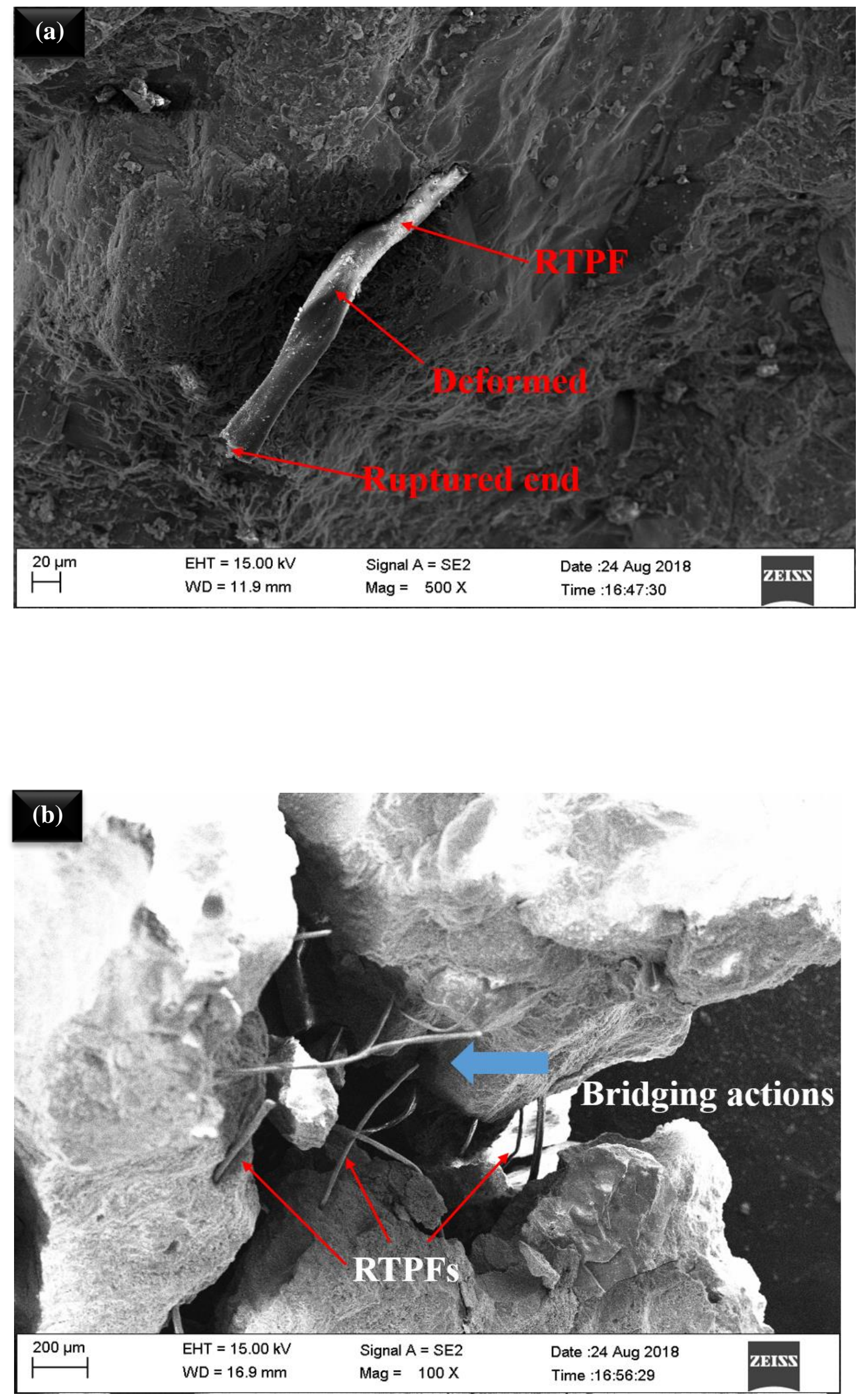

Fig. 19. SEM images of RTPF inside the concrete matrix 

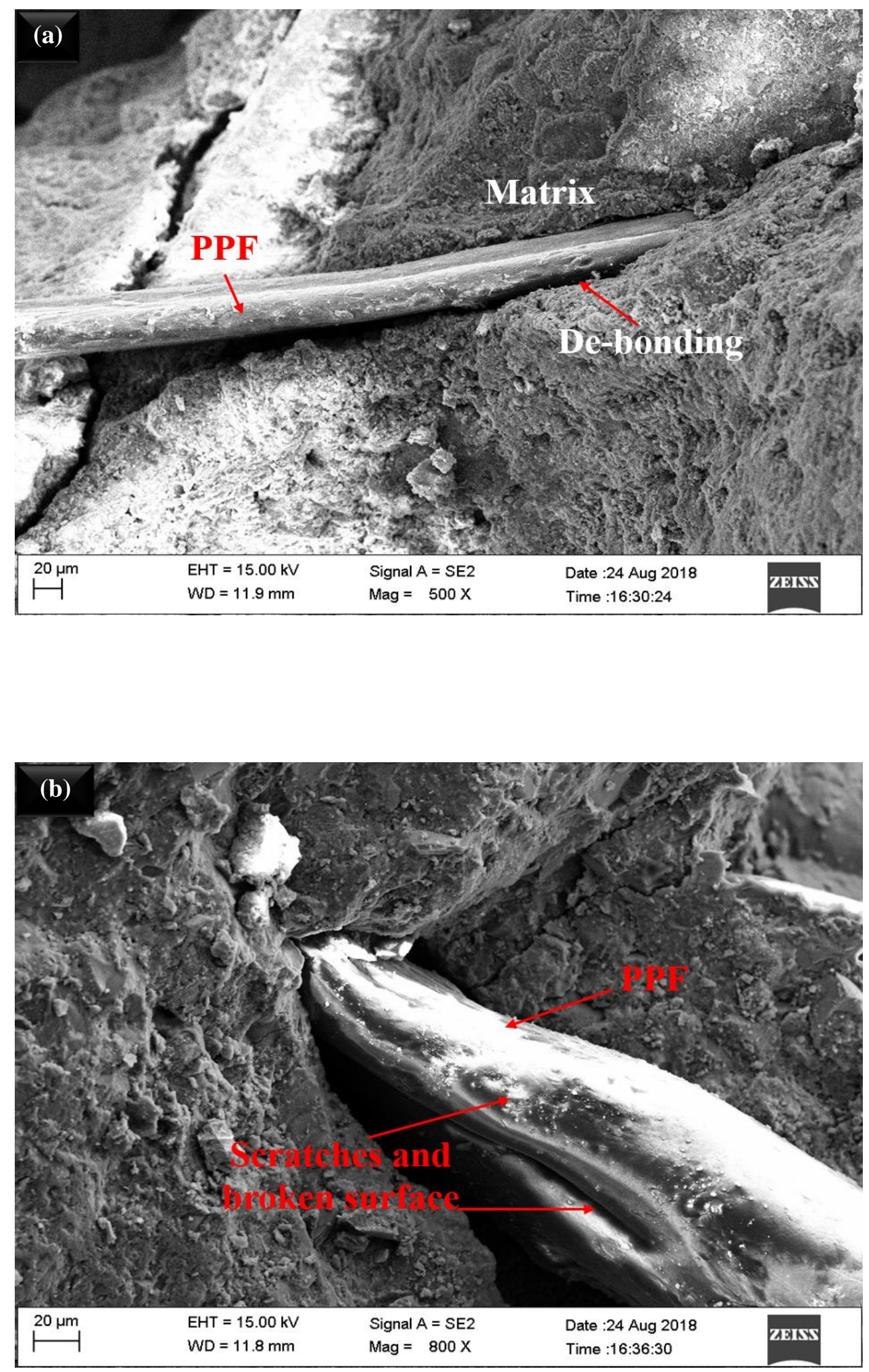

Fig. 20. SEM images of PPF inside the concrete matrix 
Tables:

Table 1 Chemical composition of cement

\begin{tabular}{ccccccccc}
\hline Oxide & $\mathrm{CaO}$ & $\mathrm{SiO}_{2}$ & $\mathrm{Al}_{2} \mathrm{O}_{3}$ & $\mathrm{Fe}_{2} \mathrm{O}_{3}$ & $\mathrm{MgO}$ & $\mathrm{SO}_{3}$ & $\mathrm{Na}_{2} \mathrm{O}$ & $\mathrm{LOI}$ \\
\hline Cement & 60.56 & 21.35 & 5.98 & 2.91 & 2.22 & 2.05 & 0.21 & 4.72 \\
\hline
\end{tabular}

Table 2 Properties of fibres

\begin{tabular}{ccccccc}
\hline Fibre type & $\begin{array}{c}\text { Length } \\
(\mathrm{mm})\end{array}$ & $\begin{array}{c}\text { Diameter } \\
(\mu \mathrm{m})\end{array}$ & $\begin{array}{c}\text { Density } \\
\left(\mathrm{kg} / \mathrm{m}^{3}\right)\end{array}$ & $\begin{array}{c}\text { Melting point } \\
\left({ }^{\circ} \mathrm{C}\right)\end{array}$ & $\begin{array}{c}\text { Fibre strength } \\
(\mathrm{MPa})\end{array}$ & $\begin{array}{c}\text { Elastic modulus } \\
(\mathrm{GPa})\end{array}$ \\
\hline PPF & 19 & 26 & 910 & $\geq 165$ & 376 & 3.79 \\
\hline RTPF & $8.7 \pm 4.1$ & $21.1 \pm 2.5$ & 1160 & $\geq 210$ & 475 & 3.21 \\
\hline
\end{tabular}

Note: PPF (polypropylene fibre); RTPF (recycled tyre polymer fibre)

Table 3 Mixture proportions

\begin{tabular}{ccccccccccc}
\hline No. & Symbol & $\begin{array}{c}\text { Cement } \\
\left(\mathrm{kg} / \mathrm{m}^{3}\right)\end{array}$ & $\begin{array}{c}\text { FA } \\
\left(\mathrm{kg} / \mathrm{m}^{3}\right)\end{array}$ & $\begin{array}{c}\mathrm{CA} \\
\left(\mathrm{kg} / \mathrm{m}^{3}\right)\end{array}$ & $\begin{array}{c}\text { Water } \\
\left(\mathrm{kg} / \mathrm{m}^{3}\right)\end{array}$ & $\begin{array}{c}\mathrm{SPs} \\
\left(\mathrm{kg} / \mathrm{m}^{3}\right)\end{array}$ & $\begin{array}{c}\mathrm{PPF} \\
\left(\mathrm{kg} / \mathrm{m}^{3}\right)\end{array}$ & $\begin{array}{c}\mathrm{RTPF} \\
\left(\mathrm{kg} / \mathrm{m}^{3}\right)\end{array}$ & $\begin{array}{c}\text { PPF } \\
\text { PPT }\end{array}$ & RTP \\
\hline 1 & F0 & 550 & 560 & 1128 & 154 & 5.5 & 0.0 & 0.0 & $/$ & $/$ \\
2 & PPF09 & 550 & 560 & 1128 & 154 & 5.5 & 0.9 & 0.0 & 0.1 & $/$ \\
3 & RTPF12 & 550 & 560 & 1128 & 154 & 5.5 & 0.0 & 1.2 & $/$ & 0.1 \\
4 & RTPF24 & 550 & 560 & 1128 & 154 & 5.5 & 0.0 & 2.4 & $/$ & 0.2 \\
5 & RTPF48 & 550 & 560 & 1128 & 154 & 5.5 & 0.0 & 4.8 & $/$ & 0.4 \\
6 & RTPF96 & 550 & 560 & 1128 & 154 & 5.5 & 0.0 & 9.6 & $/$ & 0.8 \\
\hline
\end{tabular}

Note: FA (fine aggregate); CA (coarse aggregate); SPs (superplasticisers); $\mathrm{V}_{\mathrm{f}}$ (fibre volume fraction)

Table 6 Summary of the fitted DIF equations for different mixtures

\begin{tabular}{cccc}
\hline No. & Symbol & Fitted equation of DIF & Correlation coefficient $\left(\mathrm{R}^{2}\right)$ \\
\hline 1 & F0 & $D I F=1.912 \log \dot{\varepsilon}-2.391$ & 0.955 \\
2 & PPF09 & $D I F=2.344 \log \dot{\varepsilon}-3.109$ & 0.989 \\
3 & RTPF12 & $D I F=2.227 \log \dot{\varepsilon}-2.935$ & 0.960 \\
4 & RTPF24 & $D I F=2.580 \log \dot{\varepsilon}-3.502$ & 0.978 \\
5 & RTPF48 & $D I F=2.230 \log \dot{\varepsilon}-2.875$ & 0.960 \\
6 & RTPF96 & $D I F=2.657 \log \dot{\varepsilon}-3.517$ & 0.939 \\
\hline
\end{tabular}


Table 4 Number of performed tests per test set-up (test type), per testing age and per strain rate type

\begin{tabular}{|c|c|c|c|c|c|c|c|c|c|c|}
\hline \multirow[b]{2}{*}{ Symbol } & \multicolumn{2}{|c|}{ Test set-up/type } & \multicolumn{2}{|c|}{ Testing age $(\mathrm{d})$} & \multicolumn{6}{|c|}{ Strain rate type $\left(\mathrm{s}^{-1}\right)$} \\
\hline & $\begin{array}{l}\text { Compression } \\
\text { machine (static } \\
\text { compressive } \\
\text { strength) } \\
\end{array}$ & $\begin{array}{c}\text { SHPB equipment } \\
\text { (dynamic compressive } \\
\text { behaviour) }\end{array}$ & 7 & 28 & 40 & 60 & 75 & 95 & 110 & 120 \\
\hline F0 & 6 & 18 & 3 & 21 & 3 & 3 & 3 & 3 & 3 & 3 \\
\hline PPF09 & 6 & 18 & 3 & 21 & 3 & 3 & 3 & 3 & 3 & 3 \\
\hline RTPF12 & 6 & 18 & 3 & 21 & 3 & 3 & 3 & 3 & 3 & 3 \\
\hline RTPF24 & 6 & 18 & 3 & 21 & 3 & 3 & 3 & 3 & 3 & 3 \\
\hline RTPF48 & 6 & 18 & 3 & 21 & 3 & 3 & 3 & 3 & 3 & 3 \\
\hline RTPF96 & 6 & 18 & 3 & 21 & 3 & 3 & 3 & 3 & 3 & 3 \\
\hline
\end{tabular}


Table 5 Summary of dynamic properties of fibre reinforced concrete obtained from SHPB test

\begin{tabular}{|c|c|c|c|c|c|c|c|c|}
\hline Symbol & $\begin{array}{l}\text { Average strain rate } \\
\qquad\left(\mathrm{s}^{-1}\right)\end{array}$ & $\begin{array}{c}\text { Maximum } \\
\text { dynamic stress } \\
(\mathrm{MPa})\end{array}$ & $\begin{array}{c}\text { Strain at } \\
\text { peak stress } \\
\left(\times 10^{-3}\right) \\
\end{array}$ & $\begin{array}{l}\text { Ultimate strain } \\
\qquad\left(\times 10^{-3}\right)\end{array}$ & $\begin{array}{c}\text { Static } \\
\text { compressive } \\
\text { strength }(\mathrm{MPa})\end{array}$ & DIF & $\begin{array}{l}\text { Fracture energy } \\
(\mathrm{J})\end{array}$ & $\begin{array}{c}\text { Total energy } \\
\text { (J) }\end{array}$ \\
\hline \multirow[t]{6}{*}{ F0 } & 37.8 & $39.2 \pm 2.33$ & 6.53 & 7.94 & $67.3 \pm 1.46$ & $0.58 \pm 0.035$ & $37.7 \pm 2.19$ & $69.4 \pm 0.56$ \\
\hline & 58.6 & $74.7 \pm 1.66$ & 11.55 & 22.25 & $67.3 \pm 1.46$ & $1.11 \pm 0.025$ & $130.6 \pm 9.50$ & $305.0 \pm 5.16$ \\
\hline & 75.6 & $78.3 \pm 5.22$ & 12.11 & 23.84 & $67.3 \pm 1.46$ & $1.16 \pm 0.078$ & $137.8 \pm 7.28$ & $336.3 \pm 6.19$ \\
\hline & 99.2 & $91.2 \pm 4.39$ & 12.82 & 26.54 & $67.3 \pm 1.46$ & $1.36 \pm 0.065$ & $156.7 \pm 6.66$ & $450.1 \pm 19.58$ \\
\hline & 111.7 & $99.1 \pm 3.46$ & 15.22 & 30.35 & $67.3 \pm 1.46$ & $1.47 \pm 0.051$ & $233.4 \pm 2.05$ & $546.6 \pm 26.44$ \\
\hline & 123.5 & $113.9 \pm 1.80$ & 14.88 & 33.78 & $67.3 \pm 1.46$ & $1.69 \pm 0.027$ & $231.3 \pm 13.33$ & $688.5 \pm 15.02$ \\
\hline \multirow[t]{6}{*}{ PPF09 } & 39.8 & $38.8 \pm 2.26$ & 6.66 & 12.71 & $63.4 \pm 1.06$ & $0.61 \pm 0.036$ & $42.9 \pm 2.94$ & $115.0 \pm 3.05$ \\
\hline & 64.6 & $75.0 \pm 1.95$ & 12.31 & 22.31 & $63.4 \pm 1.06$ & $1.18 \pm 0.031$ & $135.8 \pm 8.27$ & $309.8 \pm 6.08$ \\
\hline & 76.2 & $84.6 \pm 2.73$ & 12.87 & 24.44 & $63.4 \pm 1.06$ & $1.33 \pm 0.043$ & $144.3 \pm 11.69$ & $342.2 \pm 4.42$ \\
\hline & 96.6 & $96.2 \pm 1.19$ & 15.4 & 29.52 & $63.4 \pm 1.06$ & $1.52 \pm 0.019$ & $217.1 \pm 0.17$ & $503.8 \pm 14.49$ \\
\hline & 110.8 & $103.1 \pm 3.54$ & 15.95 & 31.31 & $63.4 \pm 1.06$ & $1.63 \pm 0.056$ & $224.4 \pm 9.08$ & $595.9 \pm 8.41$ \\
\hline & 122.8 & $115.7 \pm 1.84$ & 18.09 & 36.29 & $63.4 \pm 1.06$ & $1.82 \pm 0.029$ & $324.4 \pm 12.66$ & $741.5 \pm 10.19$ \\
\hline \multirow[t]{5}{*}{ RTPF12 } & 38.6 & $36.1 \pm 3.05$ & 5.76 & 11.37 & $65.8 \pm 1.03$ & $0.55 \pm 0.046$ & $29.2 \pm 1.50$ & $83.2 \pm 5.18$ \\
\hline & 62.2 & $76.7 \pm 3.90$ & 12.42 & 23.71 & $65.8 \pm 1.03$ & $1.17 \pm 0.059$ & $134.3 \pm 1.66$ & $329.6 \pm 7.19$ \\
\hline & 74.8 & $82.3 \pm 1.34$ & 13.51 & 25.21 & $65.8 \pm 1.03$ & $1.25 \pm 0.020$ & $146.6 \pm 12.38$ & $340.1 \pm 24.10$ \\
\hline & 95.8 & $92.9 \pm 4.64$ & 14.74 & 31.25 & $65.8 \pm 1.03$ & $1.41 \pm 0.070$ & $181.3 \pm 16.94$ & $510.0 \pm 6.25$ \\
\hline & 112.6 & $101.3 \pm 1.93$ & 17.14 & 32.18 & $65.8 \pm 1.03$ & $1.54 \pm 0.029$ & $266.6 \pm 12.16$ & $584.3 \pm 4.86$ \\
\hline
\end{tabular}




\begin{tabular}{|c|c|c|c|c|c|c|c|c|}
\hline & 118.4 & $116.6 \pm 3.34$ & 18.05 & 35.00 & $65.8 \pm 1.03$ & $1.77 \pm 0.051$ & $307.9 \pm 17.52$ & $657.1 \pm 6.86$ \\
\hline \multirow{6}{*}{ RTPF24 } & 39.2 & $36.8 \pm 3.23$ & 6.79 & 15.96 & $64.9 \pm 1.95$ & $0.57 \pm 0.050$ & $46.6 \pm 2.61$ & $137.1 \pm 4.50$ \\
\hline & 61.9 & $79.7 \pm 2.33$ & 12.51 & 23.42 & $64.9 \pm 1.95$ & $1.23 \pm 0.036$ & $144.2 \pm 8.33$ & $325.8 \pm 3.58$ \\
\hline & 76.7 & $88.4 \pm 1.59$ & 13.86 & 24.71 & $64.9 \pm 1.95$ & $1.36 \pm 0.025$ & $175.7 \pm 11.52$ & $365.4 \pm 2.53$ \\
\hline & 92.0 & $96.9 \pm 0.71$ & 15.65 & 30.47 & $64.9 \pm 1.95$ & $1.49 \pm 0.011$ & $241.9 \pm 9.75$ & $531.6 \pm 2.42$ \\
\hline & 107.8 & $109.5 \pm 2.46$ & 17.55 & 35.82 & $64.9 \pm 1.95$ & $1.69 \pm 0.041$ & $294.9 \pm 2.17$ & $690.7 \pm 13.25$ \\
\hline & 121.8 & $125.7 \pm 1.20$ & 18.21 & 37.89 & $64.9 \pm 1.95$ & $1.94 \pm 0.019$ & $336.9 \pm 20.69$ & $801.1 \pm 1.83$ \\
\hline \multirow{6}{*}{ RTPF48 } & 39.0 & $41.7 \pm 2.51$ & 7.10 & 14.85 & $64.4 \pm 1.48$ & $0.65 \pm 0.039$ & $65.5 \pm 1.19$ & $152.9 \pm 7.08$ \\
\hline & 63.0 & $80.0 \pm 0.54$ & 12.13 & 23.25 & $64.4 \pm 1.48$ & $1.24 \pm 0.008$ & $137.1 \pm 10.36$ & $329.2 \pm 13.16$ \\
\hline & 79.3 & $85.1 \pm 1.87$ & 13.46 & 24.35 & $64.4 \pm 1.48$ & $1.32 \pm 0.029$ & $153.0 \pm 12.50$ & $337.6 \pm 1.72$ \\
\hline & 92.5 & $93.5 \pm 4.15$ & 13.63 & 30.17 & $64.4 \pm 1.48$ & $1.45 \pm 0.064$ & $169.0 \pm 7.69$ & $496.3 \pm 4.28$ \\
\hline & 109.3 & $102.4 \pm 3.84$ & 16.14 & 33.18 & $64.4 \pm 1.48$ & $1.59 \pm 0.060$ & $244.6 \pm 14.55$ & $610.5 \pm 31.16$ \\
\hline & 119.3 & $119.5 \pm 0.95$ & 16.67 & 34.96 & $64.4 \pm 1.48$ & $1.86 \pm 0.015$ & $268.0 \pm 19.35$ & $692.1 \pm 5.08$ \\
\hline \multirow[t]{6}{*}{ RTPF96 } & 43.3 & $41.0 \pm 1.04$ & 7.97 & 17.51 & $55.4 \pm 0.60$ & $0.74 \pm 0.019$ & $53.2 \pm 5.33$ & $147.0 \pm 3.57$ \\
\hline & 60.7 & $76.9 \pm 2.79$ & 13.33 & 23.53 & $55.4 \pm 0.60$ & $1.39 \pm 0.050$ & $135.3 \pm 10.55$ & $314.1 \pm 3.14$ \\
\hline & 74.6 & $81.4 \pm 2.50$ & 14.35 & 25.65 & $55.4 \pm 0.60$ & $1.47 \pm 0.045$ & $165.6 \pm 3.39$ & $363.4 \pm 6.53$ \\
\hline & 97.4 & $92.6 \pm 4.62$ & 14.39 & 30.12 & $55.4 \pm 0.60$ & $1.67 \pm 0.083$ & $169.1 \pm 14.19$ & $453.6 \pm 5.14$ \\
\hline & 110.4 & $100.4 \pm 1.41$ & 16.14 & 33.6 & $55.4 \pm 0.60$ & $1.81 \pm 0.026$ & $232.4 \pm 15.36$ & $586.5 \pm 6.69$ \\
\hline & 118.6 & $116.3 \pm 2.41$ & 16.72 & 35.56 & $55.4 \pm 0.60$ & $2.10 \pm 0.043$ & $239.9 \pm 5.86$ & $648.5 \pm 20.74$ \\
\hline
\end{tabular}

